\title{
The Cloud Feedback Model Intercomparison Project (CFMIP) Diagnostic Codes Catalogue - metrics, diagnostics and methodologies to evaluate, understand and improve the representation of clouds and cloud feedbacks in climate models
}

\author{
Yoko Tsushima $^{1}$, Florent Brient ${ }^{2}$, Stephen A. Klein ${ }^{3}$, Dimitra Konsta ${ }^{4}$, Christine C. Nam ${ }^{5}$, Xin $\mathbf{Q u}^{6}$, \\ Keith D. Williams ${ }^{1}$, Steven C. Sherwood ${ }^{7}$, Kentaroh Suzuki $^{8}$, and Mark D. Zelinka ${ }^{3}$ \\ ${ }^{1}$ Met Office Hadley Centre, Exeter, UK \\ ${ }^{2}$ Centre National de Recherches Météorologiques, Toulouse, France \\ ${ }^{3}$ Cloud Processes Research and Modeling Group, Lawrence Livermore National Laboratory, \\ Livermore, USA \\ ${ }^{4}$ National Observatory of Athens, Athens, Greece \\ ${ }^{5}$ Institute for Meteorology, Universitaet Leipzig, Leipzig, Germany \\ ${ }^{6}$ Department of Atmospheric and Oceanic Sciences, University of California, Los Angeles, USA \\ ${ }^{7}$ Climate Change Research Centre and ARC Centre of Excellence for Climate System Science, \\ University of New South Wales, Sydney, Australia \\ ${ }^{8}$ Atmosphere and Ocean Research Institute, University of Tokyo, Kashiwa, Japan \\ Correspondence to: Yoko Tsushima (yoko.tsushima@metoffice.gov.uk)
}

Received: 14 March 2017 - Discussion started: 21 April 2017

Revised: 15 September 2017 - Accepted: 21 September 2017 - Published: 27 November 2017

\begin{abstract}
The CFMIP Diagnostic Codes Catalogue assembles cloud metrics, diagnostics and methodologies, together with programs to diagnose them from general circulation model (GCM) outputs written by various members of the CFMIP community. This aims to facilitate use of the diagnostics by the wider community studying climate and climate change. This paper describes the diagnostics and metrics which are currently in the catalogue, together with examples of their application to model evaluation studies and a summary of some of the insights these diagnostics have provided into the main shortcomings in current GCMs. Analysis of outputs from CFMIP and CMIP6 experiments will also be facilitated by the sharing of diagnostic codes via this catalogue.

Any code which implements diagnostics relevant to analysing clouds - including cloud-circulation interactions and the contribution of clouds to estimates of climate sensitivity in models - and which is documented in peer-reviewed studies, can be included in the catalogue. We very much wel-
\end{abstract}

come additional contributions to further support community analysis of CMIP6 outputs.

\section{Introduction}

Cloud feedback remains the largest source of uncertainty associated with estimates of climate sensitivity using current global climate models. Evaluation of clouds is necessary not only for the assessment of model performance, but also for understanding how the representation of the key physical processes contributes to the errors and uncertainties. CFMIP coordinates various experiments and the production of specific output variables to help improve our understanding of cloud-climate feedback mechanisms and processes.

To facilitate the evaluation of clouds in models using satellite observations, CFMIP has developed the CFMIP Observation Simulator Package (COSP; Bodas-Salcedo et al., 2011). In addition, new satellite data sets have been produced which 
diagnose cloud properties from the observations in the same way as is done in the simulator, e.g. by using the same criteria for cloud detection. An example of this is the GCMOriented Cloud-Aerosol Lidar and Infrared Pathfinder Satellite Observation (CALIPSO) Cloud Product (GOCCP) described in Chepfer et al. (2010). This ensures that discrepancies between models and observations reveal genuine biases in the models' simulation of cloud, rather than, for example, simply highlighting differences in the definition of cloud coverage.

A range of methodologies, metrics and diagnostics have been developed, many of which utilize information on clouds derived from the observational simulators. Use of these tools has led to considerable progress being made in understanding the uncertainties and errors associated with GCM cloud simulations over the last decade. In order for this understanding to eventually be reflected in better estimates of cloud feedbacks and climate sensitivity, it is vital to continue to develop such tools and to exploit them fully during the model development process.

To facilitate the wider use of these tools in the climate modelling community, repositories have been set up to store and document the programs which allow their computation. The CFMIP Diagnostics Code Catalogue lists the up-to-date repositories. Initially, a collection of repositories was set up as a part of the EU Cloud Intercomparison, Process Study \& Evaluation Project (EUCLIPSE; http://www.euclipse.eu/ index.html). Subsequent contributions have followed as a result of advertising the catalogue at various meetings and via the CFMIP mailing list. Other such collections of diagnostic codes have also been developed. The US CLIVAR MJO Working Group (Waliser et al., 2009) produced a collection of diagnostics and metrics for CMIP5 which reflected shortcomings in the representation of processes that may be relevant to the simulation of the MJO (https://www.ncl.ucar.edu/ Applications/mjoclivar.shtml). These scripts were applied to CMIP5 models to evaluate their simulations of various aspects of the Madden-Julian Oscillation (e.g. climate variability and predictability; see Waliser et al., 2009; Kim et al., 2009, 2014). The Program for Climate Model Diagnosis and Intercomparison (PCMDI) at Lawrence Livermore National Laboratory has developed common statistical error measures to compare results from climate model simulations to observations, which have been applied to the CMIP data (e.g. Gleckler et al., 2008). This collection of wellestablished large- to global-scale mean climatological performance metrics provides a baseline analysis package for CMIP: the PCMDI Metrics Package (PMP; Gleckler et al., 2016). The Earth System Model eValuation Tool (ESMValTool; Eyring et al., 2016) has been developed for CMIP6 to enable routine comparisons of single or multiple models, against either predecessor versions or observations. The current priority for PMP and ESMValTool is to target selected essential climate variables (ECVs; Gleckler et al., 2008; Pincus et al., 2008; Reichler and Kim, 2008), which include rel- ative space-time root-mean square errors (RMSEs) for some cloud and radiation parameters. Among the diagnostics in the current CFMIP catalogue, the Cloud Regime Error Metric for the annual mean climatology in the present climate (Williams and Webb, 2009) has recently been included in ESMValTool.

All of this work contributes to the wider community efforts to improve the representation of models. The World Climate Research Program (WCRP) Grand Challenges represent areas of emphasis in climate science where there is believed to be likelihood of significant progress over the next 5-10 years. One requirement for these areas is to implement effective and measurable performance metrics, to build and strengthen collaborations between communities. The CFMIP Diagnostics Codes Catalogue will contribute to this purpose for the Clouds, Circulation and Climate Sensitivity Grand Challenge (Bony et al., 2015).

This paper is a companion paper to the CFMIP description paper for CMIP6 (Webb et al., 2017). In this paper we describe code repositories and introduce diagnostics which are currently available in GitHub repositories. A general description of the repositories is provided in Sect. 2. In Sect. 3 the individual metrics and diagnostics are described and examples of their application to model development and understanding uncertainties are presented. Section 4 discusses some of the insights these diagnostics have provided into the main shortcomings in current GCMs, together with an outline of possible future work in this area.

\section{General description of the repositories and the catalogue}

The repositories are maintained and managed by the author of the associated diagnostic code.

In each repository, a README file and wiki page provide an introduction to the diagnostic and list the appropriate references. Different authors use different programming languages and the codes which are currently in the repository are provided in their original languages. The code repository is structured so that a version of the code in a different language can be placed in a different directory, allowing users to select the version they prefer to use. Details of each diagnostic, such as the required input data, the outputs generated by the program and links to the source of the required observations, are also provided in the repository. For most diagnostics, the data are assumed to be in netCDF format, provided that the variables are requested by either CMIP or CFMIP. Sample input data and output results are provided in each repository. If the sample input data size exceeds the GitHub limit, either the location information or the contact address of the author is provided on the Readme page of each repository. Currently, the application of the repository by the user will vary according to the diagnostic required: for some diagnostics all the necessary files are present to enable the user to run a small demonstration of their use, while others require some pre- 
Table 1. A summary table of diagnostics.

\begin{tabular}{|c|c|c|c|c|}
\hline Diagnostics & Scientific target to evaluate & $\begin{array}{l}\text { Does the code read CMIP } \\
\text { data? (i.e. no pre-processing) }\end{array}$ & $\begin{array}{l}\text { Time frequency } \\
\text { of input data }\end{array}$ & $\begin{array}{l}\text { What auxiliary data } \\
\text { are needed/provided? }\end{array}$ \\
\hline Klein et al. (2013) & ISCCP global cloud amounts & $\mathrm{Y}$ & Monthly & $\begin{array}{l}\text { Processed obs } \\
\text { data/Y }\end{array}$ \\
\hline $\begin{array}{l}\text { Williams and Webb (2009), } \\
\text { Tsushima et al. (2013) annual }\end{array}$ & $\begin{array}{l}\text { Annual mean climatology } \\
\text { of cloud regimes }\end{array}$ & $\mathrm{Y}$ & Daily & $\begin{array}{l}\text { Processed obs } \\
\text { data/Y }\end{array}$ \\
\hline Tsushima et al. (2013) seasonal & $\begin{array}{l}\text { Climatological seasonal cycle } \\
\text { of cloud regimes }\end{array}$ & $\mathrm{Y}$ & Daily & $\begin{array}{l}\text { Processed obs } \\
\text { data/Y }\end{array}$ \\
\hline Zelinka et al. (2012) & Cloud radiative kernels & $\mathrm{Y}$ & Monthly & $\begin{array}{l}\text { Radiative } \\
\text { Kernel/Y }\end{array}$ \\
\hline Nam and Quaas (2012) & $\begin{array}{l}\text { Zonal plots of GCM cloud } \\
\text { and hydrometeor fraction }\end{array}$ & $\begin{array}{l}\mathrm{Y} \text { (post-processing } \\
\text { done in script) }\end{array}$ & Monthly & N/A \\
\hline Konsta et al. (2015) & Instantaneous A-train & $\begin{array}{l}\mathrm{N} \\
\text { cloud property }\end{array}$ & $\begin{array}{l}\text { 8-hourly } \\
\text { Or daily }\end{array}$ & N/A \\
\hline $\begin{array}{l}\text { Nam et al. (2012) } \\
\text { vertical distribution }\end{array}$ & $\begin{array}{l}\text { Vertical distribution } \\
\text { of low clouds }\end{array}$ & $\begin{array}{l}\text { Y (post-processing } \\
\text { done in script) }\end{array}$ & Monthly & N/A \\
\hline Nam et al. (2012) albedo & $\begin{array}{l}\text { SW CRE and PARASOL reflectance } \\
\text { of low clouds }\end{array}$ & $\begin{array}{l}\mathrm{Y} \text { (post-processing } \\
\text { done in script) }\end{array}$ & Monthly & N/A \\
\hline Suzuki et al. (2015) & $\begin{array}{l}\text { Warm rain microphysical } \\
\text { process diagrams }\end{array}$ & $\mathrm{N}$ & 6-hourly & $\begin{array}{l}\text { Processed obs } \\
\text { data/Y }\end{array}$ \\
\hline Brient and Schneider (2016) & $\begin{array}{l}\text { Sensitivity of tropical low-cloud } \\
\text { reflection to SST at various } \\
\text { timescales }\end{array}$ & $\mathrm{N}$ & Monthly & $\begin{array}{l}\text { Processed obs } \\
\text { data/Y }\end{array}$ \\
\hline Qu et al. (2014) & $\begin{array}{l}\text { Sensitivities of low-cloud } \\
\text { cover to EIS and SST }\end{array}$ & $\mathrm{Y}$ & Monthly & N/A \\
\hline Sherwood et al. (2014) & $\begin{array}{l}\text { Lower tropospheric } \\
\text { mixing indices }\end{array}$ & $\mathrm{Y}$ & Monthly & N/A \\
\hline
\end{tabular}

processing of the model output and auxiliary material. The input data format and time frequency, and whether any auxiliary data are needed and provided, are summarized in Table 1 for the current version of the diagnostics described in this paper. The repositories are likely to evolve over time. To access the code versions used in this paper, please see the Supplement, where links to all of the GMD-documented diagnostics are listed. There is no selection process for a diagnostic to be added to this catalogue. The only criterion for inclusion is that the usefulness of the diagnostic has been demonstrated in a multi-model (or multi-version) comparison in a peer-reviewed paper and that the code repository is created in GitHub, following the instructions noted above. Basic instructions on how to create a repository are given in https: //github.com/tsussi/cfmip-diagnostics-code-repository.

\section{Description of metrics, diagnostics and methodologies}

Here we describe the diagnostics and metrics which are currently to be found in the catalogue. For each diagnostic Table 1 summarizes its scientific target and the practical details of its application. We start with diagnostics related to all types of clouds, followed by those focussed specifically on low-level cloud. The final group consists of diagnostics targeted at understanding cloud feedbacks. In this paper the term "metric" refers to scalar quantities which can be easily compared to observations.

\subsection{Simulation of ISCCP global cloud amounts (Klein et al., 2013)}

This code is available at https://github.com/mzelinka/ klein2013-cloud-error-metrics.

This is a set of four scalar measures of model fidelity in simulating clouds, where the observational "truth" is taken to be the International Satellite Cloud Climatology Project (ISCCP) cloud fields (Rossow and Schiffer, 1999). These are root-mean-square differences in the space-time distributions (i.e. from $60^{\circ} \mathrm{S}$ to $60^{\circ} \mathrm{N}$ through the climatological annual cycle) of cloud variables, normalized by the space-time standard deviation of the variable from the observations. These variables are (a) the total cloud amount for clouds with optical depth $>1.3$; (b) the amount of optically intermediate and thick clouds at low, middle and high levels of the atmosphere; and the impacts of optically intermediate and thick clouds on top-of-atmosphere (c) shortwave and (d) longwave radiation computed using the cloud radiative kernels (Zelinka et al., 2012; see Sect. 3.3 below). Figure 1 shows a summary of these measures of fidelity of CFMIP model simulations in reproducing the space-time distributions of several cloud measures, with greater fidelity indicated by smaller values, for representations of total cloud amount (a), cloud-top pressure 


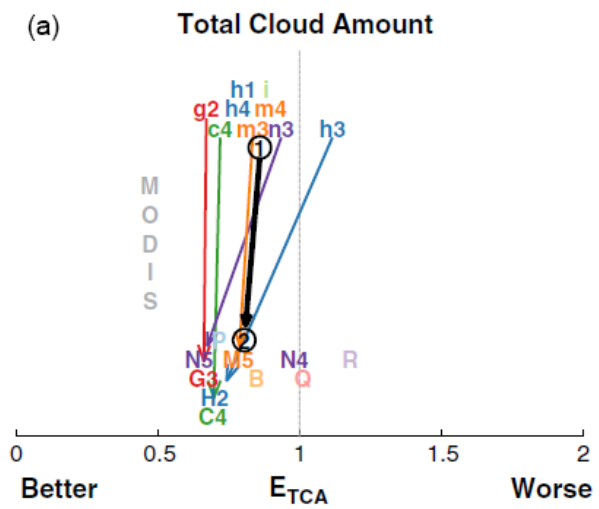

(c) SW-Relevant Cloud Properties

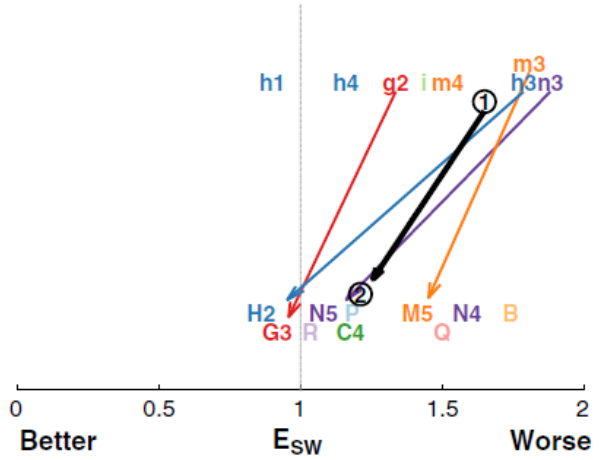

(b)

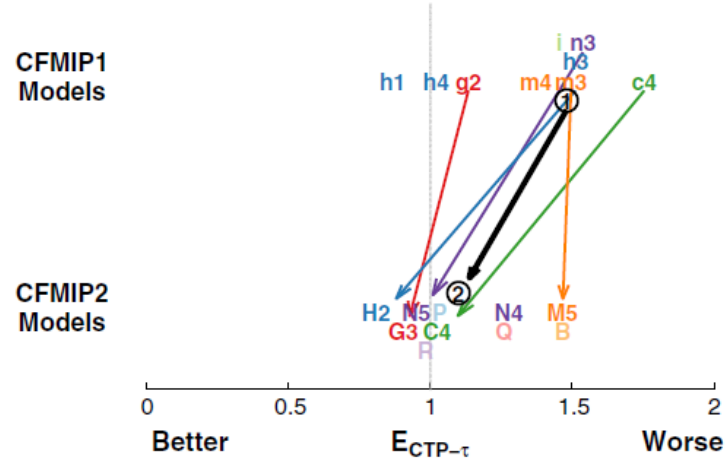

(d)

LW-Relevant Cloud Properties

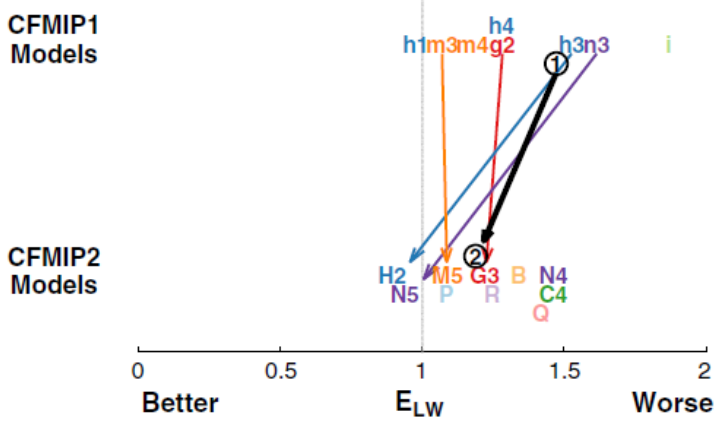

Figure 1. Scalar measures of fidelity of CFMIP model simulations in reproducing the space-time distribution of several cloud measures, with greater fidelity indicated by lower $E$ values. $E_{\mathrm{TCA}}(\mathbf{a})$ measures fidelity in simulating total cloud amount, whereas Ectp- $\tau$ (b) measures fidelity in simulating cloud-top pressure and optical depth in different categories of optically intermediate and thick clouds at high, middle, and low levels of the atmosphere. The impacts on top-of-atmosphere shortwave and longwave radiation in the same categories used for Ectp$\tau$ are measured by $E_{\mathrm{SW}}(\mathbf{c})$ and $E_{\mathrm{LW}}(\mathbf{d})$, respectively. Models are stratified vertically into the two ensembles and are plotted in different symbol keys. (To identify a model in a symbol key, see Klein et al., 2013.) For the modelling centres in which we can track progress, the arrow connects the oldest model in the family (arrow base) to the most recent model (arrow tip). The thick black arrow connects the average measure of CFMIP1 models (arrow base) to that of CFMIP2 models (arrow tip). Arrows pointing to the left indicate improvements with time. Reprinted from Klein et al. (2013).

and optical depth (b), and the impacts on top-of-atmosphere shortwave (c) and longwave radiation (d). CFMIP1 models are symbols at the arrow base and CFMIP2 models are symbols at the arrow top. Arrows pointing to the left indicate improvement with time. The thick black arrow connects the average measure of CFMIP1 models (arrow base) to that of CFMIP2 models (arrow top). As a point of comparison, we also use roughly analogous observations from the MODerate resolution Imaging Spectrometer (MODIS) instruments for the period March 2000 through April 2011 (Pincus et al., 2012). In Fig. 1a, the $E_{\mathrm{TCA}}$ measure between the MODIS and ISCCP climatologies is 0.47. All model differences with ISCCP exceed this value, so it is likely that errors in the climatology of total cloud amount are robustly determined. Most individual models and the ensembles as a whole show progress over time in most measures of simulation fidelity, with small improvements for the representations of total cloud amount and large improvement for the distributions of cloud optical properties and their impact on shortwave radiation. The diagnostic codes are available at https://github.com/mzelinka/klein2013-cloud-error-metrics.

\subsection{Cloud Regime Error Metric (CREM; Williams and Webb, 2009; Tsushima et al., 2013)}

This code is available at https://github.com/tsussi/ cloud-regime-error-metric.

This is a set of scalar metrics which summarize the overall ability of a model to simulate the cloud radiative effects (CREs) of a set of different cloud regimes. The ISCCP observational cloud regimes were obtained using the KMEANS clustering algorithm (Anderberg, 1973) and an empirical method to choose the number of clusters (Rossow et al., 2005). (For details, see Williams and Tselioudis, 2007.) Using daily mean data the cloud regime assigned to a model grid box is the observational regime which has the minimum 
Euclidean distance in the vector space of normalized daily mean cloud-top pressure, optical depth and cloud cover. Each metric is a single scalar value, so it is easy to compare different models or different versions of the same model. These metrics can also be broken down into contributions from different cloud regimes (Eq. 1).

$M^{2}=\frac{\sum_{i=1}^{n} w_{i} m_{i}^{2}}{n}$,

where $n$ is the total number of the cloud regimes, $w$ is the respective area weight for the region where the regime $i$ is defined (e.g. $20^{\circ} \mathrm{S}-20^{\circ} \mathrm{N}$ tropics, Northern Hemisphere extratropics beyond $20^{\circ} \mathrm{N}$ ), and $m_{i}$ is the error in simulating the regime $i$, which quantifies the distance from the observations, as defined below.

\subsubsection{Evaluation of the annual mean climatology of cloud regimes}

This is a single scalar metric which evaluates the climatological annual mean net CRE over the chosen number of cloud regimes.

The model rms error (RMSE) associated with each regime $i\left(a_{i}\left(\mathrm{Wm}^{-2}\right)\right)$ can be approximated with two components: the error in the relative frequency of occurrence $\left(f_{i}^{\prime}\right)$ compared to the observations $\left(f_{i}^{o}\right)$ and the error in the net CRE when the regime occurs (the in-regime net CRE) $\left(C_{i}{ }^{\prime}\right)$ compared to the observations $\left(C_{i}^{o}\right)$ :

$a_{i}=\sqrt{\left(f_{i}^{\prime} C_{i}^{o}\right)^{2}+\left(f_{i}^{o} C_{i}{ }^{\prime}\right)^{2}}$.

Figure 2 shows changes between the CFMIP-1 and CFMIP-2 models in these error components for the $a_{i}$ in the net CRE in the tropics $\left(20^{\circ} \mathrm{S}-20^{\circ} \mathrm{N}\right)$. Improvements in the CFMIP2 models relative to those in CFMIP1 are seen mainly in the cloud radiative properties, i.e. in the error components for the in-regime net $\operatorname{CRE}\left(f_{i}^{o} C_{i}{ }^{\prime}\right)$, rather than those for the frequency of occurrence $\left(f_{i}{ }^{\prime} C_{i}^{o}\right)$. This is especially true for deep convective cloud, anvil cirrus, stratocumulus, transition and shallow cumulus cloud regimes.

\subsubsection{Evaluation of the climatological seasonal cycle of cloud regimes}

This scalar metric evaluates variations of climatological monthly mean net CRE over the chosen number of cloud regimes.

An error in the climatological annual variation of the CRE for regime $i$ can be caused by an error in the amplitude of the variation and an error in the pattern (e.g. phase, shape) of the time variation. The centred rms error of the climatological seasonal variation of the CRE for regime $\left(s_{i}\right)$ relative to the observations is expressed as

$s_{i}^{2}=\left(\sigma_{i, \mathrm{~m}}-\sigma_{i . o}\right)^{2}+2 \sigma_{i, \mathrm{~m}} \sigma_{i, \mathrm{o}}(1-R)$, where $\sigma_{i, \mathrm{o}}$ and $\sigma_{i, \mathrm{~m}}$ denote the standard deviation of the climatological monthly mean of observed and modelled CREs for a regime $i$ from the climatological annual mean, and $R$ is the linear correlation coefficient between the anomaly (difference from the annual mean) of the model and that of the observation over the 12 months of the seasonal cycle. We use these standard deviations as a measure of the amplitude in the seasonal variation. The error in the amplitude of the variation $\left(s_{i, \text { amp }}\right)$ is defined by

$s_{i, \mathrm{amp}}=\sigma_{i, \mathrm{~m}}-\sigma_{i, \mathrm{o}}$.

The second term of $s_{i}$ is a covariance term between the observations and the model. We define the error in the pattern of the time variation $\left(s_{i, \mathrm{cov}}\right)$ as

$s_{i, \mathrm{Cov}}=\sqrt{2 \sigma_{i, \mathrm{~m}} \sigma_{i, \mathrm{o}}(1-R)}$

(see Tsushima et al., 2013, for details).

The seasonal variation of the shortwave CRE (SCRE) is attributable to not only the variation of clouds, but also to that of the incoming solar radiation. To evaluate the variation of shortwave radiative components by clouds in models, it is thus necessary to remove the latter but keep the former. This is achieved by normalizing the SCRE by the local solar insolation.

Figure 3 shows the seasonal variation of the normalized SCRE (NSCRE) of cloud regimes in the tropics $\left(20-20^{\circ} \mathrm{N}\right)(\mathrm{a})$, Northern Hemisphere extra-tropics beyond $20^{\circ} \mathrm{N}$ (b), and Southern Hemisphere extra-tropics beyond $20^{\circ} \mathrm{S}$ (c) in five CMIP5 models. The seasonal variation of the NSCRE is relatively well simulated by the models in the tropics: the largest inter-model spread is in the stratocumulus regime and the main differences between models relate to variations in the amplitude of the seasonal cycle.

\subsection{Cloud radiative kernels (Zelinka et al., 2012)}

This code is available at https://github.com/mzelinka/ cloud-radiative-kernels.

The cloud radiative kernels quantify the sensitivity of the top-of-atmosphere (TOA) radiative fluxes to cloud fraction perturbations within the seven cloud-top pressure categories and seven cloud optical depth categories defined by ISCCP (Fig. 4). Multiplying the cloud radiative kernels - which are a function of latitude, month, and surface albedo - by changes in cloud fraction (segregated on the same cloud-top pressureoptical depth grid) between two climate states yields a quantitative estimate of the cloud-induced TOA radiation anomalies. Normalizing these by the change in global mean surface temperature between the two climate states then provides a measure of cloud feedback.

Because the kernels are computed using a single radiative transfer code (Fu and Liou, 1992), differences in cloud feedbacks among climate models can be unambiguously attributed to inter-model differences in the responses of clouds. 

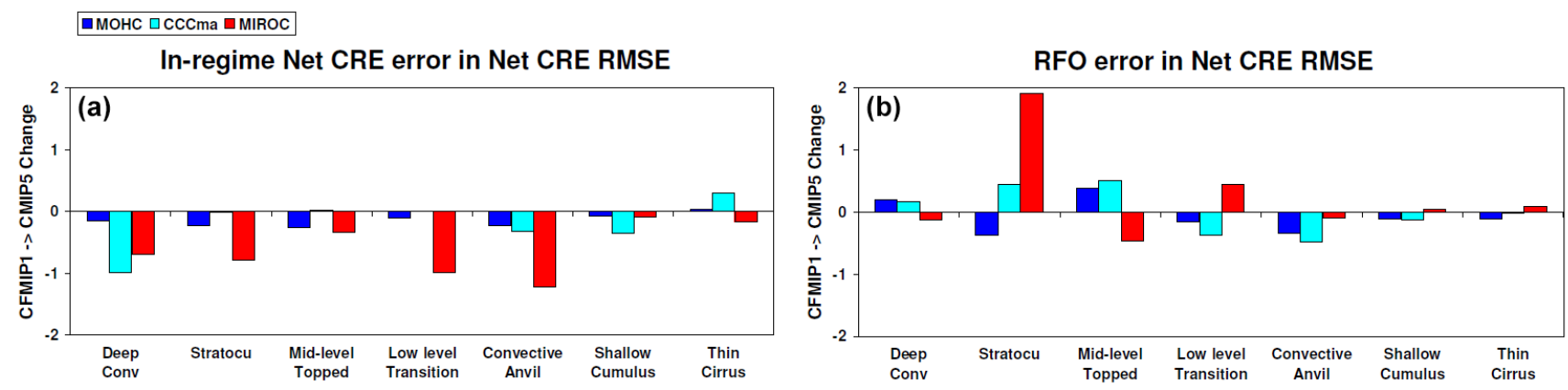

Figure 2. Changes between CFMIP-1 and CFMIP2 of RMSE components of $a_{i}$ for net CRE within daily ISCCP simulator cloud regimes in the tropics. (a) In-regime net CRE components $\left(f_{i}^{o} C_{i}{ }^{\prime}\right)$; (b) frequency of occurrence components $\left(f_{i}{ }^{\prime} C_{i}^{0}\right)$. Cloud regimes are in the order of larger albedo. Graphs drawn using the values in Table 2 in Tsushima et al. (2013).

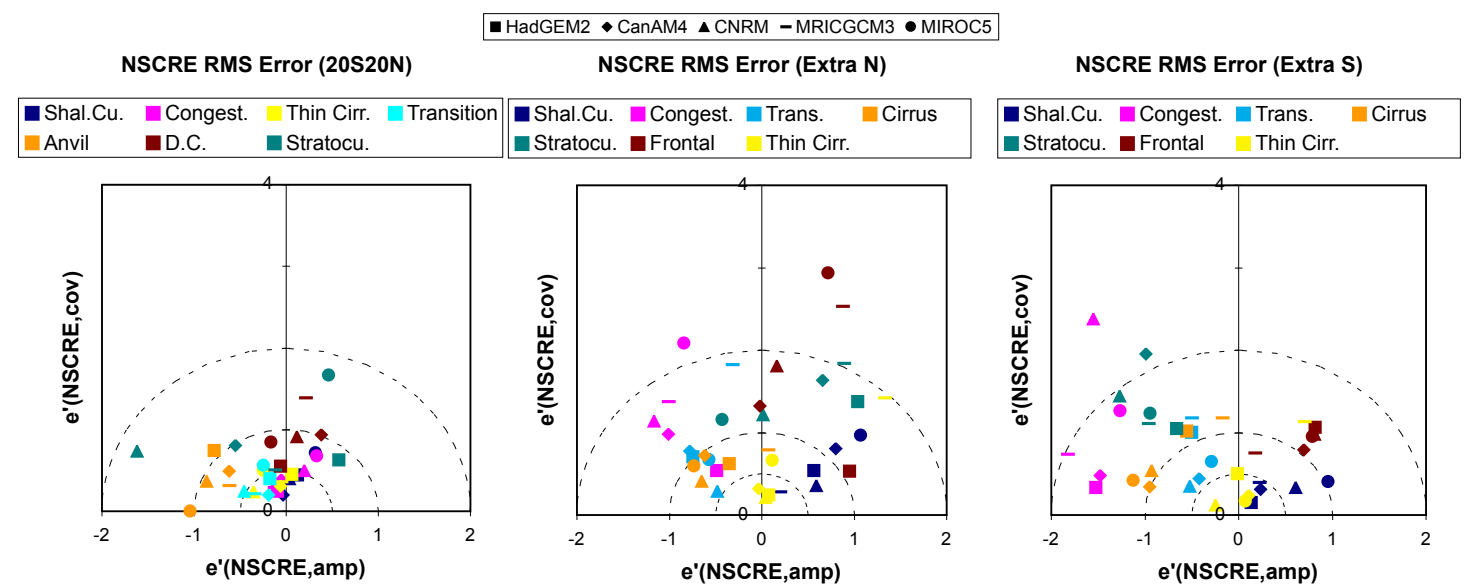

Figure 3. Centred rms error diagrams of the seasonal variation of NSCRE of cloud regimes in (a) $20^{\circ} \mathrm{S}-20^{\circ} \mathrm{N}$, (b) northern extra-tropics beyond $20^{\circ} \mathrm{N}$, and (c) southern extra-tropics beyond $20^{\circ} \mathrm{S}$. Colours distinguish cloud regimes. Marks distinguish models. The dotted lines are contours of the magnitude of $s_{i}$ (NSCRE). The $x$-axis shows the contribution of amplitude error, while the $y$-axis shows the contribution of pattern errors in the time variation. Reprinted from Tsushima et al. (2013).

Furthermore, because the cloud feedback is computed directly from changes in cloud fields rather than inferred from TOA fluxes, no adjustments are necessary to account for noncloud-induced radiative flux anomalies. The kernels can also be applied to a model's control simulation and observations (Klein et al., 2013; see Sect. 3.1) to quantify radiative flux errors contributed from different cloud types in a model, or to two model versions to quantify the impact of the changes in different cloud types in a new version of the model on errors in radiative fluxes.

The panels on the right-hand side of Fig. 5 show CFMIP1 slab-ocean simulations' ensemble mean cloud radiative feedback contributions from different cloud categories in (d) longwave, (e) shortwave and (f) net, expressed per unit change in each model's global mean surface air temperature between the two states. These estimates of cloud feedbacks are produced by multiplying the change in cloud fraction at each location and month by the collocated radiative kernels. This figure highlights the various cloud types that contribute to the cloud feedback. High cloud changes make large but opposing contributions to the LW and SW cloud feedbacks. Low- and mid-level cloud changes, which are negative in most bins, make a strong positive contribution to the SW cloud feedback, especially at optical depths greater than 3.6 where the kernel is larger in magnitude. Because these contributions are not strongly opposed in the LW, the net cloud feedback for mid- and low-level clouds arises primarily from the SW component.

\subsection{Zonal plots of GCM cloud and hydrometeor fraction compared with CALIPSO-GOCCP and CloudSat (Nam and Quaas, 2012)}

This code is available at https://github.com/chriscnam/ CFMIP_LidarRadar.

This code produces plots of zonally averaged vertical profiles of cloud fraction and hydrometeor fraction from the active-sensor satellite observations and models. Comple- 
(a) Longwave

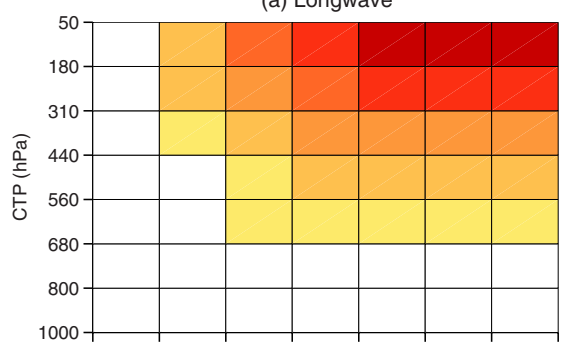

(b) Shortwave

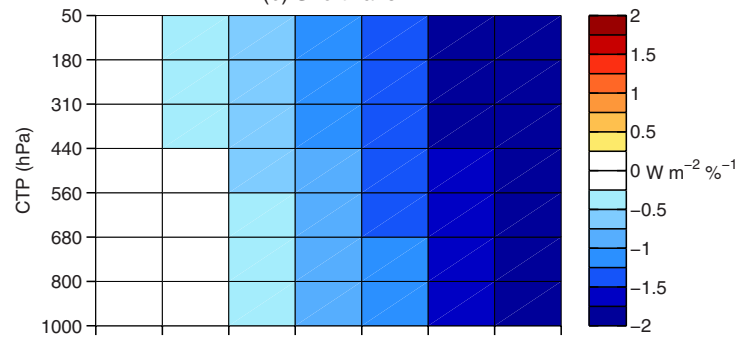

(C) Net

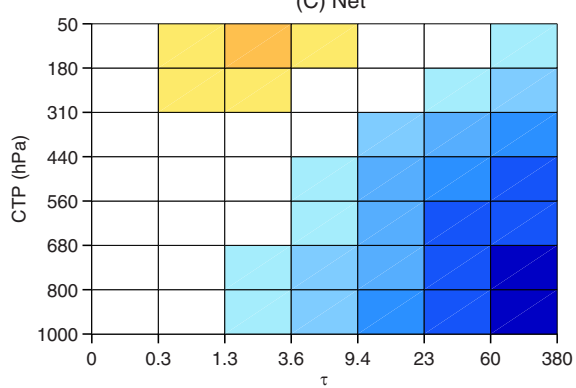

Figure 4. Global, annual, and ensemble mean (a) LW, (b) SW, and (c) net cloud radiative kernels. In each model, the kernels have been mapped to the control climate's clear-sky surface albedo distribution before averaging in space; thus, the average kernels are weighted by the actual global distribution of clear-sky surface albedo in each model. Redrawn with modification from Zelinka et al. (2012).

menting the ISCCP simulator referred to above, the active lidar and radar satellite simulators emulate the radiances which would be retrieved by the CALIPSO and CloudSat instruments within climate models. The active lidar and radar simulators allow a more accurate comparison of the vertical distribution of clouds and hydrometeors in climate models with the CALIPSO-GOCCP and CloudSat 2B-GeoProf data sets (Marchand et al., 2009). Figure 6 shows the zonally averaged cloud fraction (top row; Fig. 6a-c) and hydrometeor fraction (bottom row; Fig. 6d-e) for June-July-August 2007 from (a) CALIPSO-GOCCP data; (b) the IPSL5B GCM with the COSP Lidar Simulator; (c) the IPSL5B GCM; (d) CloudSat data; and (e) the IPSL5B GCM with the COSP Radar Simulator (Nam and Quaas, 2012; Chepfer et al., 2010; Marchand et al., 2009). From these plots, one can identify model biases such as the overestimate of optically thin high-level clouds and the significant underestimate of mid-level and (sub)tropical low-level clouds. In addition, it can be seen that IPSL5B overestimates the frequency of precipitation. These findings imply that compensating mechanisms in IPSL5B balance out the radiative imbalance caused by incorrect optical properties of clouds and consistently large hydrometeors in the atmosphere, which was also found for ECHAM5 in Nam and Quaas (2012).

\subsection{A-train satellite instantaneous cloud property observations for process-oriented evaluation (CALIPSO-PARASOL; Konsta et al., 2015)}

This code is available at https://github.com/dimitrakonsta/ process-oriented-cloud-evaluation.

These 2-D histograms correlate different cloud variables from the multi-sensor A-train observations at the instantaneous timescale, and at high spatial resolution. This allows us to see how different key cloud properties vary as a function of one another (Konsta et al., 2012) and to build pictures of cloud processes which are well suited for the evaluation of clouds in climate models.

Specifically, the histogram shows the relationship between cloud cover from CALIPSO (Winker et al., 2007) and cloud reflectance measured by PARASOL (Parol et al., 2004), which is a good surrogate of the cloud optical depth. The same relationship is reproduced for the model using the COSP simulator.

Figure 7 provides the instantaneous (upper panels) and monthly mean (lower panels) relationship between the cloud cover and the cloud reflectance over the tropical oceans for the observations (a, d) and as simulated by two versions of the LMDZ5 model using COSP (b, c, e, f). In the observations, the cloud reflectance tends to increase with increasing cloud cover, but the models do not reproduce this relationship in either the instantaneous data or the monthly mean. However, the two panels show that the relationship between cloud fraction and cloud optical thickness is very different when using monthly mean and instantaneous values, both in observations and in the models. This joint data analysis of different instantaneous observations allows for a more precise evaluation of cloud properties and model parameterizations. 
(a) $1 \times \mathrm{CO}_{2}$ Mean Cloud Fraction: $58.12 \%$

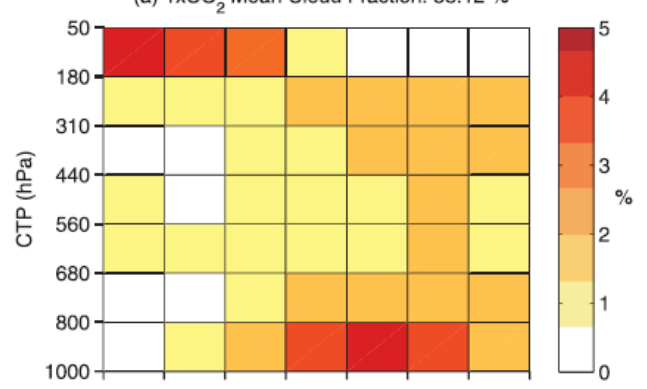

(b) $2 \times \mathrm{CO}_{2}$ Mean Cloud Fraction: $56.81 \%$

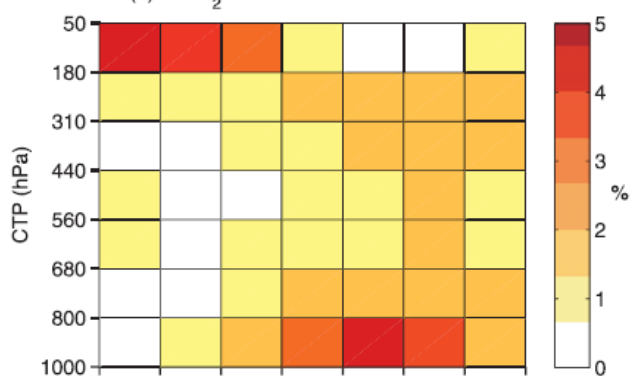

(c) $\Delta$ Cloud Fraction: $-0.46 \% K^{-1}$

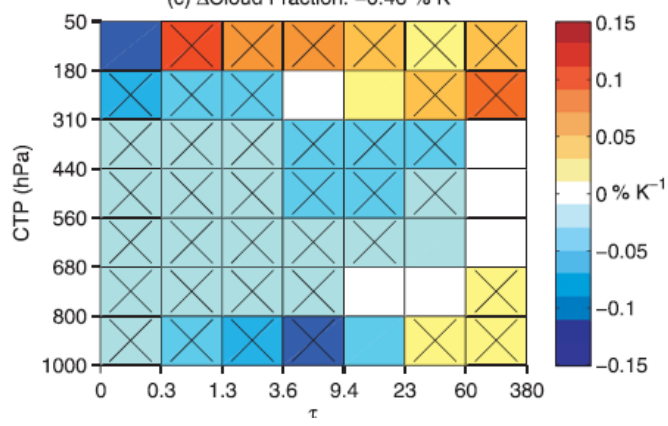

(d) LW Cloud Feedback: $0.21 \mathrm{~W} \mathrm{~m}^{-2} \mathrm{~K}^{-1}$

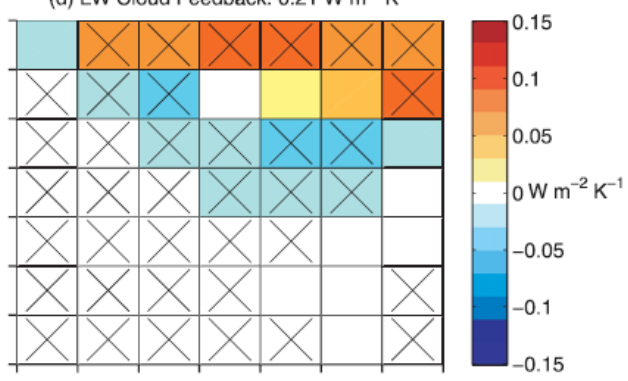

(e) SW Cloud Feedback: $0.37 \mathrm{~W} \mathrm{~m}^{-2} \mathrm{~K}^{-1}$

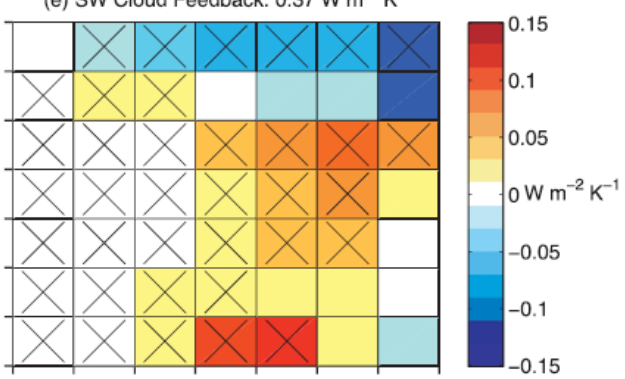

(f) Net Cloud Feedback: $0.57 \mathrm{~W} \mathrm{~m}^{-2} \mathrm{~K}^{-1}$

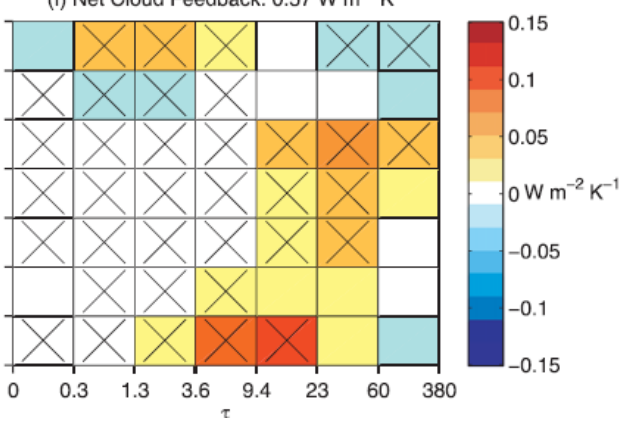

Figure 5. Global, annual, and ensemble mean cloud fractions for the (a) $1 \times \mathrm{CO}_{2}$ and (b) $2 \times \mathrm{CO}_{2}$ runs, along with (c) the average difference expressed per unit change in each model's global mean surface air temperature between the two states. Matrix resulting from multiplying the change in cloud fraction at each location and month by the collocated (d) LW, (e) SW, and (f) net cloud radiative kernels, and then taking the global, annual, and ensemble means. The sum of each matrix is shown in each title. Bins containing an " $\times$ " indicate those in which $\geq 75 \%$ of the models agree on the sign of the field plotted. Reprinted from Zelinka et al. (2012), @American Meteorological Society. Used with permission.

\subsection{Low-level cloud distribution and optical properties: CALIPSO, PARASOL, CERES (Nam et al., 2012)}

\subsubsection{Vertical distribution of low-level clouds}

This code is available at https://github.com/chriscnam/ CFMIP_LowCloudDistribution.

These histograms show the frequency of occurrence of clouds below $4 \mathrm{~km}$ over the tropical oceans $\left(30^{\circ} \mathrm{N}-30^{\circ} \mathrm{S}\right)$ in the observations and models (Fig. 8). This diagnostic, from Nam et al. (2012), identifies non-overlapped (i.e. by mid- and high-level cloud) low-level clouds within subsiding regimes. This is done by first identifying where large-scale vertical velocities at 500 and $700 \mathrm{hPa}$ are greater than $10 \mathrm{hPa}$ day $^{-1}$; then distinguishing between shallow cumulus and stratocumulus regimes using the lower tropospheric stability thresh- old of 18.55 K, as defined in Medeiros and Stevens (2011); and finally testing whether lidar-defined high- and mid-level cloud covers are both less than $5 \%$. The histogram demonstrates that CMIP5 models tend to concentrate their low clouds in the lowest $1 \mathrm{~km}$ of the troposphere, regardless of the large-scale environment, instead of distributing them throughout the boundary layer.

\subsubsection{Shortwave cloud radiative effect (SW CRE) and PARASOL reflectance}

This code is available at https://github.com/chriscnam/ CFMIP_SWCRE_Parasol.

The poor vertical distributions of low-level clouds shown above lead to biases in their optical properties, which can be quantified using this diagnostic: the mean SW CRE and 


\section{Zonal Hydrometeor Fraction 2008 JJA}
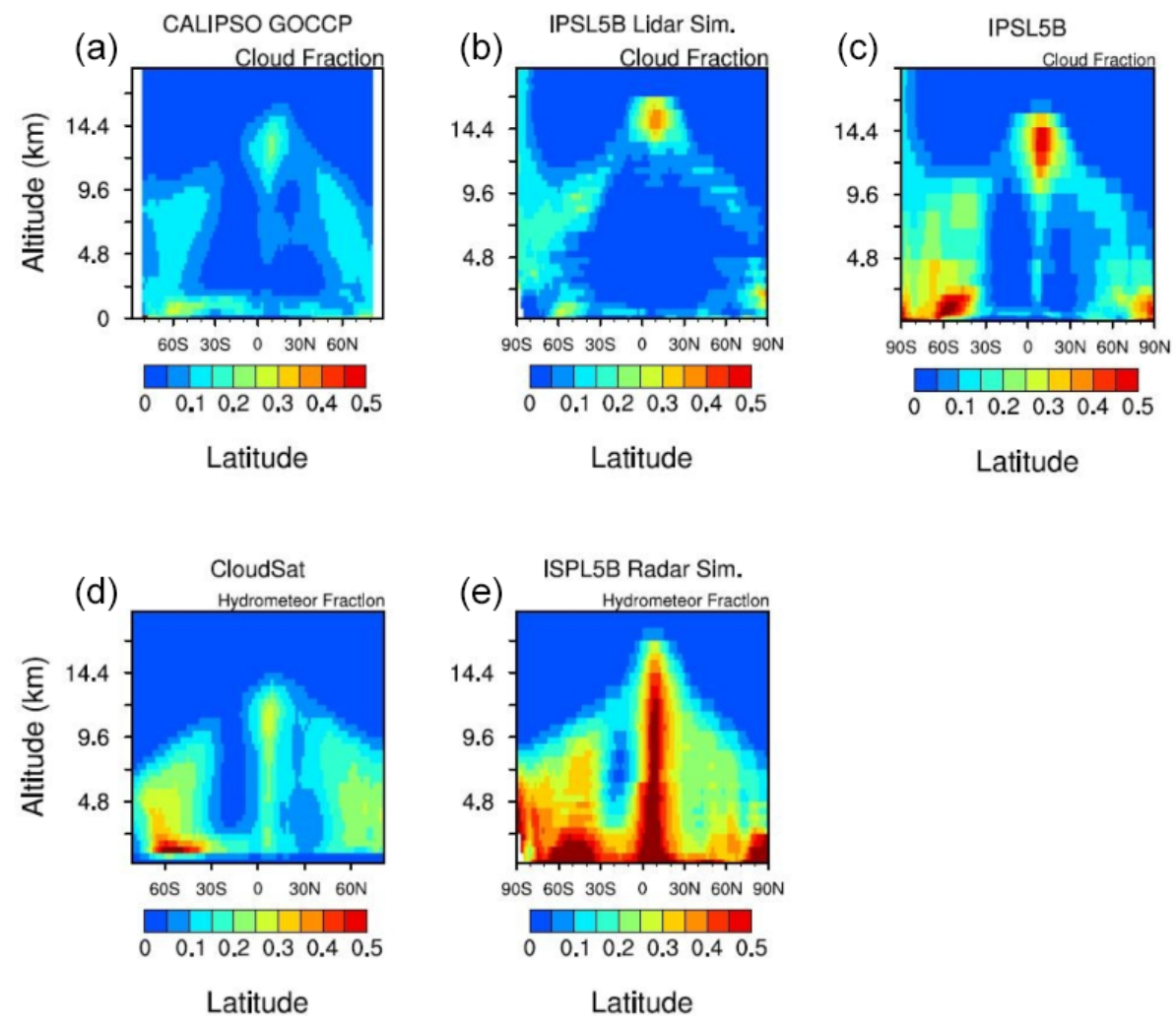

Figure 6. Zonal cloud and hydrometeor fraction for JJA 2007. Cloud fraction (top row): (a) CALIPSO-GOCCP data, (b) IPSL5B with the CALIPSO simulator, and (c) the IPSL5B cloud fraction. Hydrometeor fraction (bottom row): (d) CloudSat data; (e) IPSL5B with the CloudSat simulator. Produced for IPSL5B with the observational data used in Nam and Quaas (2012), (CAmerican Meteorological Society. Used with permission.

PARASOL reflectance broken down into different cloud fraction bins (Fig. 9). The comparison of shortwave cloud radiative effects from various CMIP5 models with CERES TOA fluxes as well as PARASOL reflectance above the nonoverlapped low clouds (Fig. 9) show that models overestimate the cloud radiative effects compared to observations, even for comparable cloud fractions and large-scale environmental conditions (Nam et al., 2012).

\subsection{Warm rain microphysical process diagrams (Suzuki et al., 2015)}

This code is available at https://github.com/kntrszk/cfodd.

This diagnostic plots vertical profiles of radar reflectivity in the form of a contoured frequency diagram as a function of in-cloud optical depth (ICOD). The radar reflectivity is obtained from the CloudSat 2B-GEOPROF product (e.g. Marchand et al., 2008) and the cloud optical depth is obtained from the MODIS cloud product (e.g. Platnick et al., 2003; Nakajima et al., 2010). The diagram is constructed from the probability density function (PDF) of radar reflectivity at each ICOD bin, and shows the PDFs as the contoured frequency of radar reflectivity as a function of ICOD, which is referred to as the Contoured Frequency by Optical Depth Diagram (CFODD). The ICOD is determined by a vertical slicing of the total cloud optical thickness from MODIS into each radar bin according to the adiabatic growth assumption that provides a scaling function of the optical depth with respect to geometric height. When the statistics thus constructed are further classified according to the cloud-top particle size also obtained from MODIS (Platnick et al., 2003; Nakajima et al., 2010), the vertical microphysical structure and its microphysical transition from non-precipitating through drizzling to raining are clearly depicted (Suzuki et al., 2010; Nakajima et al., 2010), as shown in Fig. 10 (top panel). Corresponding statistics are also constructed from model output of satellite cloud observables obtained with the aid of appropriate satellite signal simulators such as CFMIP Observation Simulation Package (COSP; Bodas-Salcedo et al., 2011) and Satellite Data Simulation Unit (SDSU; Masunaga et al., 2010). The model-derived statistics thus synthesized (Fig. 10, lower panels) are then compared with the satellite-based statistics to identify key model biases in representing warm rain formation process characteristics. Ex- 

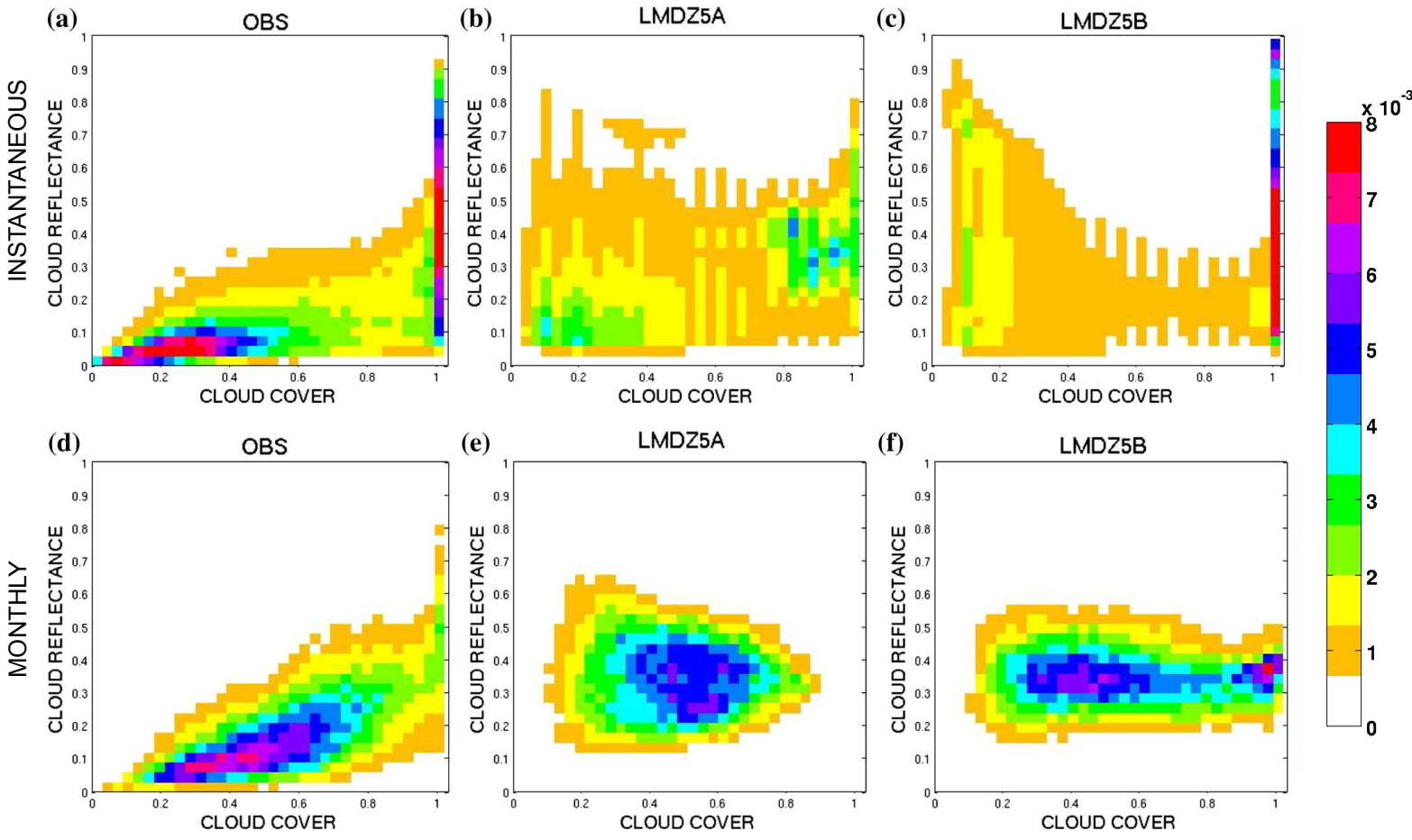

Figure 7. Two-dimensional histograms of cloud reflectance and cloud cover over the tropical oceans using instantaneous data (upper panels) and monthly data (lower panels) (a), (d) observed with PARASOL and CALIPSO-GOCCP, (b), (e) simulated with LMDZ5A and the simulator, and (c), (f) simulated with LMDZ5B and the simulator. The colour bar represents the number of points at each grid cell (cloud cover-cloud reflectance) divided by the total number of points. Reprinted with permission from Konsta et al. (2015).

amples of such an analysis with two CMIP5 models, shown in Fig. 10, demonstrate how some models share a common bias of "overly early rain formation" that happens even when the cloud-top particle sizes are small, in stark contrast to the satellite statistics (Suzuki et al., 2015).

\subsection{Sensitivity of tropical low-cloud reflection to surface temperature change at various timescales (Brient and Schneider, 2016)}

Codes for this diagnostic are available at https://github.com/ florentbrient/Cloud-variability-time-frequency and https:// github.com/florentbrient/ECS-Constraint.

This diagnostic calculates covariances of time series of any cloud-related variable (e.g. low-cloud albedo $\alpha_{\mathrm{c}}$, low-cloud fraction) and that of sea surface temperature $T$ (robust regression slope, correlation coefficients).

Brient and Schneider (2016) estimated the sensitivity of the reflectance of tropical low clouds (TLCs) to the underlying surface temperature change at intra-annual, seasonal and interannual timescales in the observations and CMIP5 models. As shown in Fig. 11, they found that in the observations on all timescales shortwave reflection by TLC decreases robustly when the underlying surface warms. They also showed that in simulations of the warmer climate reached after quadrupling carbon dioxide concentrations, higher sensitivity
(HS) models project a reduction of TLC reflection, whereas lower sensitivity (LS) models project less change or even an increase. The models' equilibrium climate sensitivity (ECS) correlates significantly with the sensitivity of cloud reflection to the underlying surface temperature warming ( $53 \%$ of the variance). Additionally, the spread in temporal covariance of low-cloud reflection with surface temperature in current climate simulations explains about half of the ECS variance across models. Therefore, recent space-based measurements of shortwave radiation permit estimation of a more likely range of ECS values, highlighting that ECS values below $2.3 \mathrm{~K}$ appear very unlikely. Code is provided to calculate a set of diagnostics based upon the covariance of two time series (robust regression slope, correlation coefficients); separation of timescales is achieved by applying low-pass and highpass filters. The calculation by the code also provides the uncertainty range underlying the covariance through a stationary bootstrap procedure. An additional program is used to constrain the more likely range of ECS values by weighting models' ability to reproduce the observed covariance between TLC reflection and sea surface temperature. 

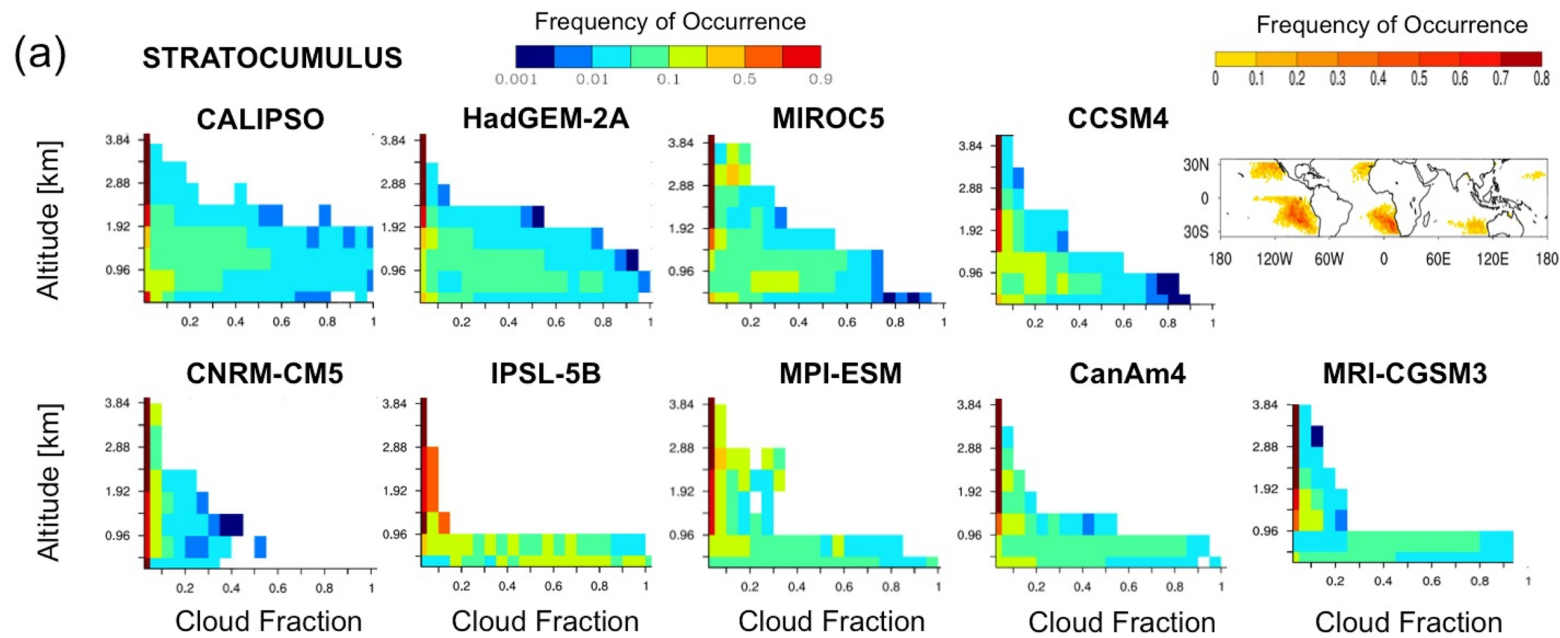

(b)

SHALLOW CUMULUS
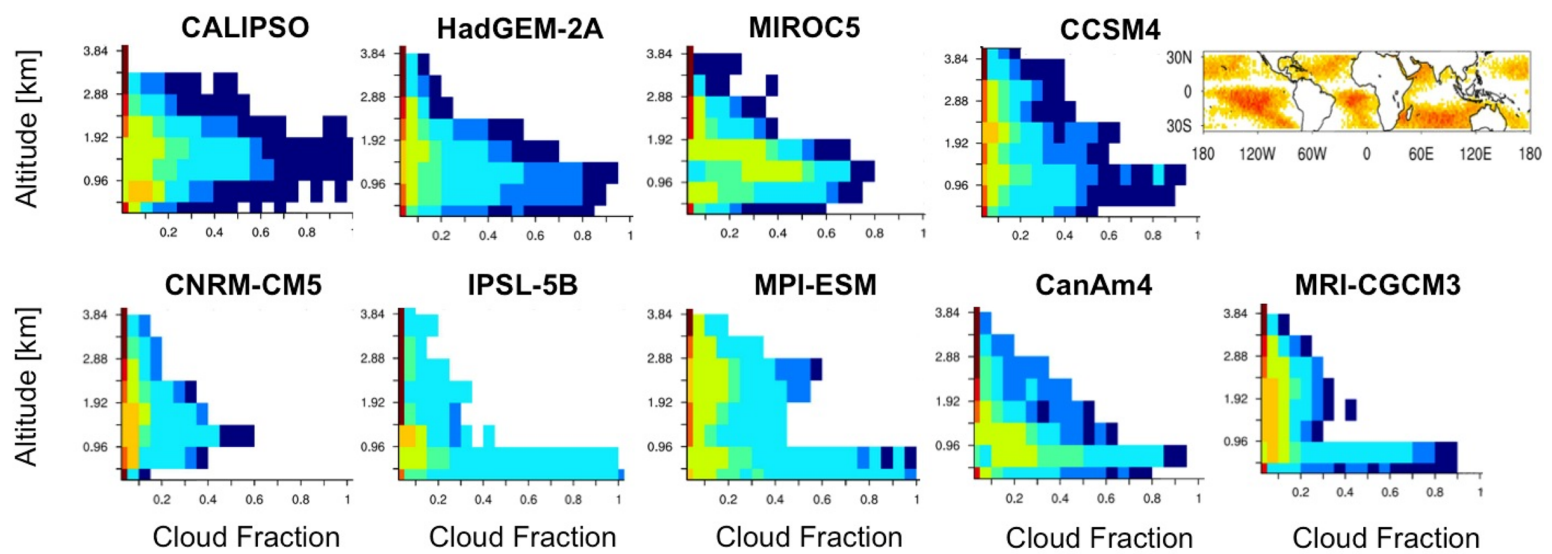

Figure 8. Comparison of the frequency of occurrence of clouds in the lowest $4 \mathrm{~km}$, of a given fraction at a given altitude under non-overlapped low-level cloud conditions for (a) a stratocumulus regime and (b) a shallow cumulus regime for the CALIPSO-GOCCP and CMIP5 models. Maps show the frequency of occurrence of each regime derived from CALIPSO observations and ERA-Interim reanalysis. Reprinted from Nam et al. (2012).

\subsection{Sensitivities of low-cloud cover to estimated inversion strength and sea surface temperature $(\mathrm{Qu}$ et al., 2014)}

This code is available at https://github.com/xinqu2016/ SST-and-EIS-slopes.

This metric calculates the sensitivity of tropical marine low-cloud cover (LCC) to two key cloud-controlling factors, the strength of the inversion capping the atmospheric boundary layer (measured by the estimated inversion strength, EIS) and sea surface temperature (SST). These parameters were developed as part of a heuristic model used to interpret change in LCC simulated in GCMs. The heuristic model's premise is that simulated LCC changes can primarily be interpreted as a linear combination of contributions from EIS and SST. For a given GCM, the respective contributions of EIS and SST are computed by multiplying (1) the sensitiv- ity of LCC to EIS and SST variations by (2) the climatechange signal in EIS or SST. The heuristic model is remarkably skillful, capturing a large portion of the variance of LCC changes across different GCMs. In particular, its SST term dominates, accounting for much of the spread in simulated LCC changes.

The sensitivities of LCC to SST and EIS (referred to as the SST and EIS slopes, respectively) were computed based on interannual variability in the 20th century via multiple regression analysis and for each of five low-clouddominated oceanic regions. Figure 12 shows the EIS slope

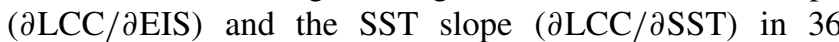
CMIP3 and CMIP5 models and the observations. According to the observations, slopes are negative for SST and positive for EIS. This suggests that LCC decreases with increasing SST but increases with increasing EIS. Modelsimulated slopes generally have signs consistent with the ob- 
(a)

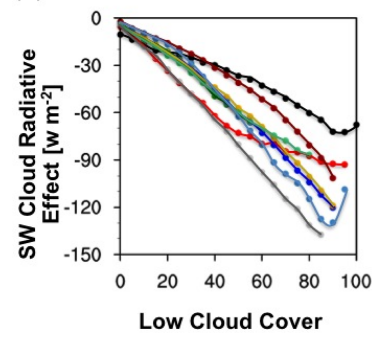

(b)

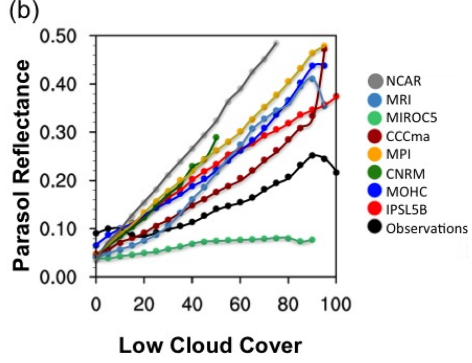

Figure 9. Mean relationship between non-overlapped low-cloud cover $(\%)$ and (a) the shortwave cloud radiative effect $\left(\mathrm{W} \mathrm{m}^{-2}\right)$; and (b) the PARASOL reflectance, derived for observations and for CMIP5 models over the tropical oceans $\left(30^{\circ} \mathrm{N}-30^{\circ} \mathrm{S}\right)$ from June 2006 to December 2008. Black: CERES and PARASOL observations, respectively; grey: NCAR; light blue: MRI; light green: MIROC5; light red: IPSL5B; dark blue: MOHC; dark green: CNRM; dark red: CCCma; orange: MPI. Redrawn with modification from Nam et al. (2012).

servations but underestimate the magnitudes of both SST and EIS slopes. The observational slopes were computed based on ISCCP cloud data (Rossow and Schiffer, 1999), ERAInterim reanalysis (Dee et al., 2011) and NOAA optimum interpolation monthly SST version 2 (Reynolds et al., 2002) during the period 1984-2009.

\subsection{Lower Tropospheric Mixing Index (Sherwood et al., 2014)}

This code is available at https://github.com/scs46/ LTMI-mixing.

The Lower Tropospheric Mixing Index (LTMI) proposed by Sherwood et al. (2014) was found to be empirically related to climate sensitivity in both the CMIP3 and CMIP5 models. The mixing diagnosed via this index is intended to capture vertical mixing not directly associated with precipitation production, such that the LTMI can also be interpreted as a measure of bulk precipitation inefficiency. Sherwood et al. (2014) argued that the relationship seen between LTMI and climate sensitivity arises because a high LTMI implies that upward moisture fluxes within the troposphere will increase relatively strongly with temperature, producing more positive global net cloud feedback by inhibiting the conditions necessary for low-cloud formation. The LTMI consists of two components, which represent two scales of vertical mixing: small-scale vertical mixing $(S)$ within a single grid column of the model, involving model parameterizations directly, and large-scale mixing $(D)$ via explicitly resolved, shallow overturning circulations. $S$ is diagnosed from vertical gradients of humidity and temperature over warm tropical oceans at altitudes around the typical marine boundarylayer top, while $D$ is calculated explicitly from model pressure velocity fields in the lower and middle troposphere. Both quantities were obtained from annual-mean data over tropi-

cal oceans, with only 2 years giving reasonably stable results compared to the large differences in mixing rates between models, although we recommend longer time periods. Figure 14 shows the relationship of ECS with $S, D$ and the LTMI (the sum of $S$ and $D$ ). Observations of $S$ and $D$ were obtained in that study from radiosonde and reanalysis data. The ranges of $D$ and $S$ are similar (Fig. 13a, b), and the LTMI explains about $50 \%$ of the variance in total system feedback $(r=0.70)$ and ECS ( $r=0.68$; Fig. 13c); thus, LTMI explains a significant portion of the model spread. In the observations, $S$ shows near the middle of the GCM range, but $D$ close to the top end, which suggests the existence of mid-level outflows stronger than models.

\subsection{Application to understanding and model development}

Here two examples are presented of how the metrics and diagnostics described in the previous section are applied to models during their development.

Bodas-Salcedo et al. (2012) applied cloud regime analysis in this catalogue (Sect. 3.2) and diagnosed cloud regimes around cyclone centres over the Southern Ocean in observations and in an atmospheric-only configuration (GA2.0) of the Met Office Unified Model. The motivation for this study was to investigate the role of clouds in the long-standing bias of surface downwelling shortwave radiation over the region. They found that low- and mid-level clouds in the cold-air sector of the cyclones are responsible for most of the bias (Fig. 14). Based on this analysis, a new diagnosis of sheardominated boundary layers was developed and was included in a newer configuration of the model.

Kamae et al. (2016) applied two diagnostics in this catalogue to a Multi-Parameter Multi-Physics Ensemble (MPMPE), which consists of both parametric and structural uncertainties in parameterizations of cloud, cumulus convection and turbulence to investigate relationships between the LTMI and equilibrium climate sensitivity (Sect. 3.11). Significant correlations were found in all of the perturbed parameter ensembles (PPEs) with different physics schemes but using an old convective scheme, but not in PPEs which used a new convective scheme. To understand the difference they used the cloud radiative kernels (Sect. 3.3) and broke down the differences into contributions from different cloud types. In both subsets of ensembles with different convective schemes they found significant positive correlations between small-scale mixing $\left(M_{\text {small }}\right)$ and low-level cloud shortwave feedback $\left(\lambda_{S W_{c l d}}\right)$, i.e. the larger the mixing, the more positive the cloud feedback. Although middle-level cloud shortwave feedbacks also have significant correlations with $M_{\text {small }}$ in both ensembles, their signs of the correlation are the opposite, negative in the PPEs with the new convective scheme and positive in the PPEs with the old convective scheme (Fig. 15). In the PPEs with the new convective scheme, the relationships of low-level cloud feedback and middle-level 
(a) A-Train/ $/ r_{e}=5-10 \mu m$

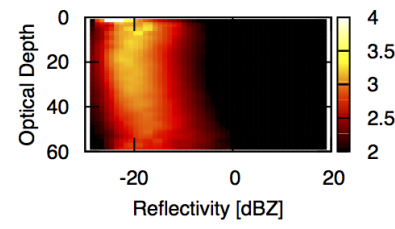

(d) HadGEM2/r $\mathrm{r}_{\mathrm{e}}=5-10 \mu \mathrm{m}$

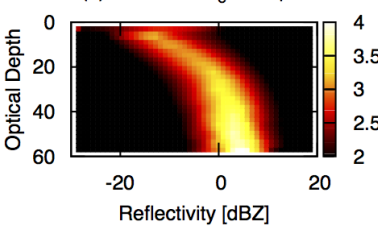

(g) $\mathrm{CM} / \mathrm{r}_{\mathrm{e}}=5-10 \mu \mathrm{m}$

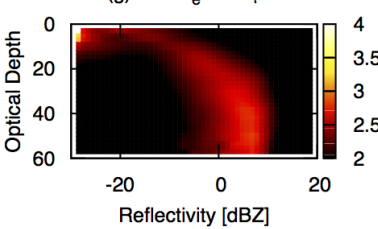

(b) A-Train $/ r_{e}=10-15 \mu \mathrm{m}$

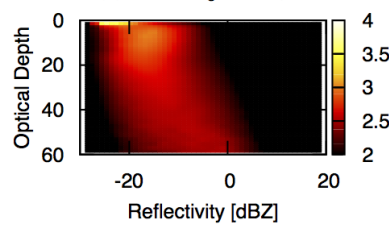

(e) HadGEM $2 / r_{\mathrm{e}}=10-15 \mu \mathrm{m}$

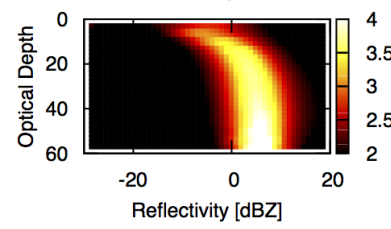

(h) $\mathrm{CM} 3 / \mathrm{r}_{\mathrm{e}}=10-15 \mu \mathrm{m}$

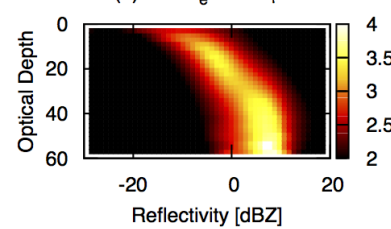

(c) A-Train/r $r_{e}=15-20 \mu \mathrm{m}$

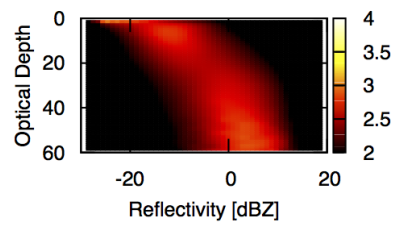

(f) $\mathrm{HadGEM} 2 / \mathrm{r}_{\mathrm{e}}=15-20 \mu \mathrm{m}$

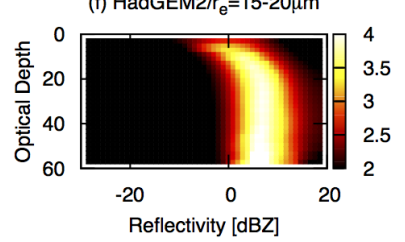

(i) $\mathrm{CM} / \mathrm{r}_{\mathrm{e}}=15-20 \mu \mathrm{m}$

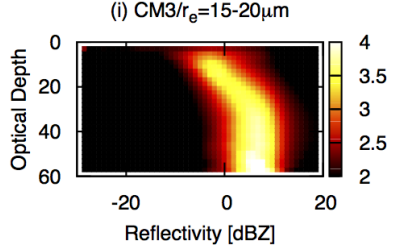

Figure 10. Examples of the CFODD statistics obtained from CloudSat and MODIS satellite observations (upper), UKMO/HadGEM2 (middle) and GFDL/CM3 (bottom) reproduced with data of Suzuki et al. (2015). The colour shading shows the probability density function of radar reflectivity $\left(\% \mathrm{dBZ}^{-1}\right)$ normalized at each in-cloud optical depth. The statistics are classified according to the cloud-top effective particle radius (left to right).

cloud feedback to small-scale mixing are opposite, and hence cancel each other. As a result, the climate sensitivity has no significant correlation with the LTMI. They suggest that a different mechanism other than lower tropospheric mixing could control middle-level cloud feedback, and there is therefore a need to develop an alternative emergent constraint.

\section{Discussion}

We have described the metrics and diagnostics that are currently available in the CFMIP Diagnostic Codes Catalogue and have provided examples of their application to model evaluation. These examples demonstrate the value of these diagnostics in understanding and reducing errors in representing clouds in climate models.

We envisage the metrics and diagnostics in this catalogue being used extensively for model evaluation studies in CMIP6, particularly as part of CFMIP. The ISCCP cloud histograms defined in terms of cloud-top pressure and cloud optical thickness have been used to understand both model errors and feedbacks in different cloud types and regimes (Klein et al., 2013; Williams and Webb, 2009; Tsushima et al., 2013, 2015; Zelinka et al., 2012). Some of these studies use instantaneous, i.e. time-step, data (e.g. Konsta et al., 2015; Suzuki et al., 2015), the motivation being to understand physical processes, as this is known to be important for understanding cloud feedbacks (e.g. Gettleman and Sherwood, 2016).
As the spread in low-cloud feedbacks in the tropics was a large contribution to the spread in climate sensitivity in both IPCC AR4 (Randall et al., 2007) and IPCC AR5 (Boucher et al., 2013), many studies have focussed on the representation of low clouds and their associated feedbacks in climate models. Indeed, about half of the diagnostics in the current catalogue are targeted at low-level clouds (Nam et al., 2012; Qu et al., 2014; Sherwood et al., 2014; Brient and Schneider, 2016; Suzuki et al., 2015). These studies have provided insights into three long-standing problems in GCMs.

a. The too few, too bright problem. Low clouds in GCMs have larger reflectance but a smaller cloud amount than the observations. Cloud reflectance sorted by cloud amount showed that models overestimate the cloud radiative effects compared to observations, even for comparable cloud amounts (Nam et al., 2012). Konsta et al. (2015) confirmed this at the instantaneous timescale. The tropical low-level cloud properties are grouped into two clusters according to the observations. One cluster corresponds to cumulus-type clouds (with low-cloud fraction and low-cloud reflectance), while the other corresponds to stratocumulus-type clouds (with an almost overcast cloud fraction and with large cloud reflectance values). However, in two versions of the LMDZ climate model (Dufresne et al., 2013; Hourdin et al., 2013a, b), these properties are not reproduced. The clouds with small cloud cover have overly large reflectance values and clouds with a cover close to one are overesti- 


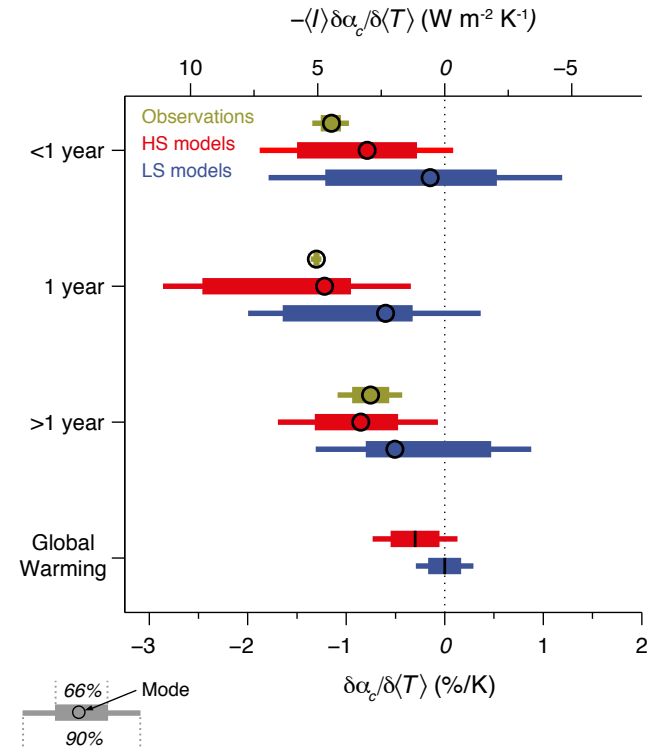

Figure 11. Observed and simulated covariance of TLC reflection with surface temperature. Twenty-nine CMIP5 models are used. Intra-annual ( $<1$ year), seasonal (1 year), and interannual ( $>1$ year) frequency bands are distinguished. The regression coefficients $\delta \alpha_{\mathrm{c}} / \delta\langle T\rangle$ are shown with their modes (most likely values) and 66 and $90 \%$ confidence intervals, for observations, 14 HS climate models, and 15 LS GCMs. Angle brackets \langle\rangle denote the mean over the TLC regions. For the models, $\delta \alpha_{\mathrm{c}} / \delta\langle T\rangle$ is also shown for global-warming simulations, calculated from the cloud reflection and temperature differences in the TLC regions between years 130-149 and years 2-11 after an abrupt quadrupling of carbon dioxide concentrations. For the global-warming simulations, the corresponding approximate confidence intervals $(0.95 \sigma$ and $1.65 \sigma)$ obtained from the standard deviation $\sigma$ of $\delta \alpha_{\mathrm{c}} / \delta\langle T\rangle$ among the HS and LS models are shown, with the bar marking the multimodel median. The upper axis indicates $-\langle I\rangle \delta \alpha_{\mathrm{c}} / \delta\langle T\rangle$, which approximates the variation of the shortwave cloud radiative effect $\left(S_{\mathrm{c}}\right)$ with temperature, $\delta\left\langle S_{\mathrm{c}}\right\rangle / \delta\langle T\rangle$. $\langle I\rangle$ is the regional mean solar insolation. Reprinted from Brient and Schneider (2016), @American Meteorological Society. Used with permission.

mated. Deficiencies which were highlighted in Nam et al. (2012) to explain the overestimate of the low-cloud radiative effect are a misrepresentation of the horizontal inhomogeneity of cloud optical properties and the vertical overlap of cloud layers. In addition, 3-D effects have a significant impact on the solar reflection, and a fast algorithm to account for this in global atmospheric models is being developed (Hogan et al., 2016). Tsushima et al. (2015) confirmed the overestimate of in-cloud albedo by comparing daily ISCCP cloud regime data with the regimes simulated in five current models. In the stratocumulus regime, models simulate smaller cloud amounts than those observed because broken cloud situations tend to occur more frequently than overcast situations, in contrast to the observations. The too frequent

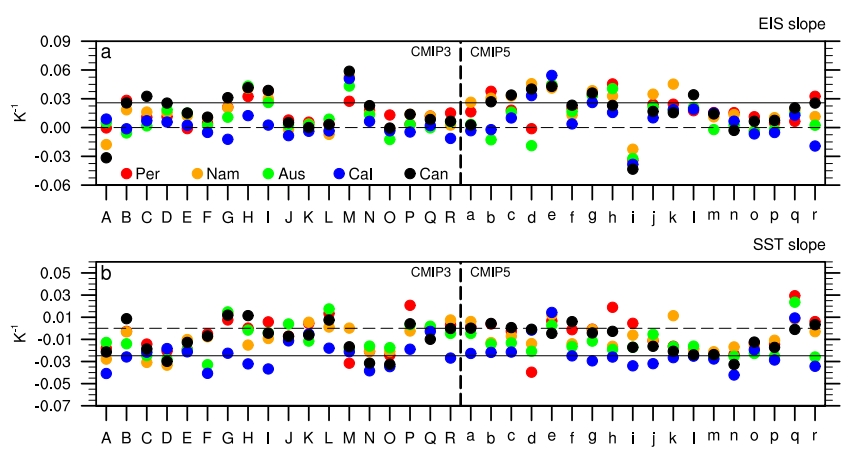

Figure 12. (a) The EIS slope ( $\partial \mathrm{LCC} / \partial \mathrm{EIS})$; (b) the SST slope $(\partial \mathrm{LCC} / \partial \mathrm{SST})$ in the five oceanic regions from 36 models in the 20th century and from the observations. Note that the observational slope values (solid lines) are the averages over the five regions. Reprinted with permission from Qu et al. (2014).

occurrence of broken clouds contributes more to the positive bias in reflectance for the stratocumulus regime than the overestimate in reflectivity for a given cloud cover. Further investigation of the reasons for the underestimate of overcast cases in models is necessary.

b. Vertical profile of low-level clouds. Nam et al. (2012) showed that GCMs poorly represent the vertical structures of low-level clouds. Sherwood et al. (2014) showed lower tropospheric mixing in GCMs is smaller than in observations and suggest that most models underestimate climate sensitivity. The mixing consists of small-scale mixing by convective and other parameterizations (e.g. Brient et al., 2016) and large-scale mixing by large-scale circulations. Whether this mixing is achieved in practice in a model will depend upon the precise details of the convection scheme, in particular the model's ability to represent shallow convection.

CFODDs (Suzuki et al., 2015) diagnose the cloud-rain conversion process which is related to the vertical distribution of lower tropospheric humidity. These diagrams show that the formation of rain from cloud droplets in GCMs (often referred to as auto-conversion) happens much faster than it does in the observations. In addition, convection schemes in GCMs tend to convert extra moisture into precipitation immediately. Zhao et al. (2016) used a developmental version of the nextgeneration Geophysical Fluid Dynamics Laboratory GCM and constructed a tightly controlled set of GCMs where only the formulation of convective precipitation is changed. They demonstrated that model estimates of climate sensitivity can be strongly affected by the rain formation process in a model's convection parameterization. The model differences are dominated by shortwave feedbacks and come from broad regimes ranging from large-scale ascent to subsidence regions. Better representation of these processes could therefore help 

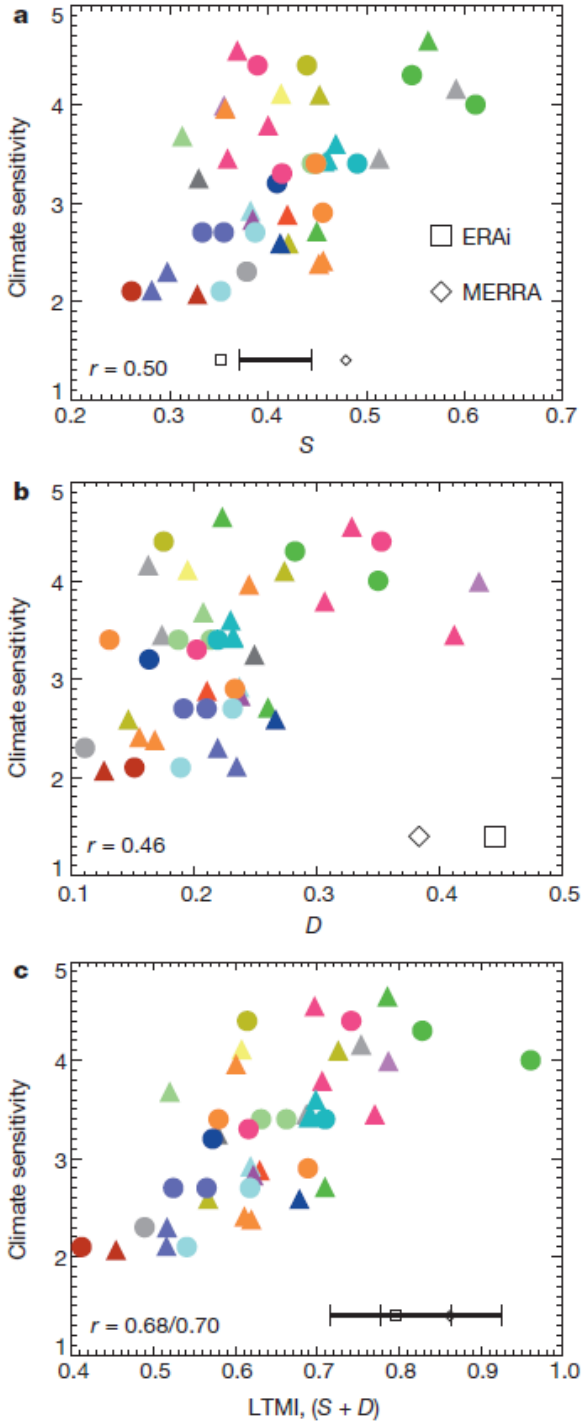

Figure 13. Scatterplot of $S$ (a), $D$ (b) and LTMI (the sum of $S$ and $D)$ (c) on the abscissa and the equilibrium climate sensitivity (on the ordinate) from 43 CMIP3 (circles) and CMIP5 models (triangles). Symbol colour identifies the modelling centre of origin. Linear correlation coefficients are given in the lower left corner of LTMI with the equilibrium climate sensitivity and the total system feedback, respectively. Two observational estimates for LTMI with error bars are shown on the abscissa, with central values indicated by the unfilled square and diamond. Reprinted from Sherwood et al. (2014).

to improve simulations of the vertical profiles of lower tropospheric humidity and clouds.

c. Low cloud amount change with SST increase. Both GCMs and process models tend to produce positive low-cloud feedbacks through a reduction of low cloud amount. However, deficiencies in the representation of low clouds in GCMs, as well as a lack of observational constraints, means that the sign of the low-cloud feedback is still very uncertain (Boucher et al., 2013). Positive low-cloud feedback in the observations in all timescales was shown by Brient and Schneider (2016). $\mathrm{Qu}$ et al. (2014) showed that interannual variations of low cloud cover decrease with increasing SST in the observations, and confirmed that models tend to reproduce this decrease in both historical and climate change simulations. They also found that inter-model variance of low cloud changes in climate change simulations is dominated by the inter-model differences in the SST increase and the sensitivity to SST. Why then does low cloud amount decrease with increasing SST in GCMs? The mechanism proposed by Sherwood et al. (2014) is that intensification of lower tropospheric mixing could dry the boundary layer and reduce cloud amount. These observational constraints of low cloud amount feedback suggest larger positive cloud feedback and hence higher climate sensitivity. These diagnostics, which identify a source of error in GCMs that relates to climate predictions, merit attention from those developing climate models and climate observations (Klein and Hall, 2015). The possible contributions of other factors to the low cloud cover change should also be examined (e.g. Webb and Lock, 2013). In large-eddy simulations (LES) at stratocumulus locations, the cloud remains overcast but thins in the warmer, moister, $\mathrm{CO} 2-$ enhanced climate, due to the combined effects of an increased lower-tropospheric vertical humidity gradient and an enhanced free-tropospheric greenhouse effect that reduces the radiative driving of turbulence (Bretherton et al., 2013). Mechanisms of low-level cloud amount change in warming climate are still not well understood, and further investigations combining observations, GCMs and process models are necessary.

Although there is a significant correlation between LTMI and ECS in both the CMIP3 and CMIP5 models, its correlation with cloud radiative feedback is weaker. Kamae et al. (2016)'s investigation of the lower tropospheric mixing using MPMPEs found that small-scale mixing has a significant correlation with low-level cloud shortwave feedbacks and also that the sign of the correlation is robust across the ensembles. Although correlations were also found with middle-level cloud shortwave feedback, the signs are not robust among the different physics ensembles. Zelinka et al. (2012) showed that high cloud changes induce wider ranges of LW and SW cloud feedbacks across models than do low clouds. Zhao et al. (2016)'s study suggests that changes in convective clouds may be as important as those in low clouds in determining climate sensitivity. Hence development of diagnostics and emergent constraints associated with different cloud types and processes would be helpful.

Underestimation of middle-top clouds has been a common bias in climate models (Zhang et al., 2005; Tsushima et al., 2014), but its implication for cloud feedbacks is currently not 

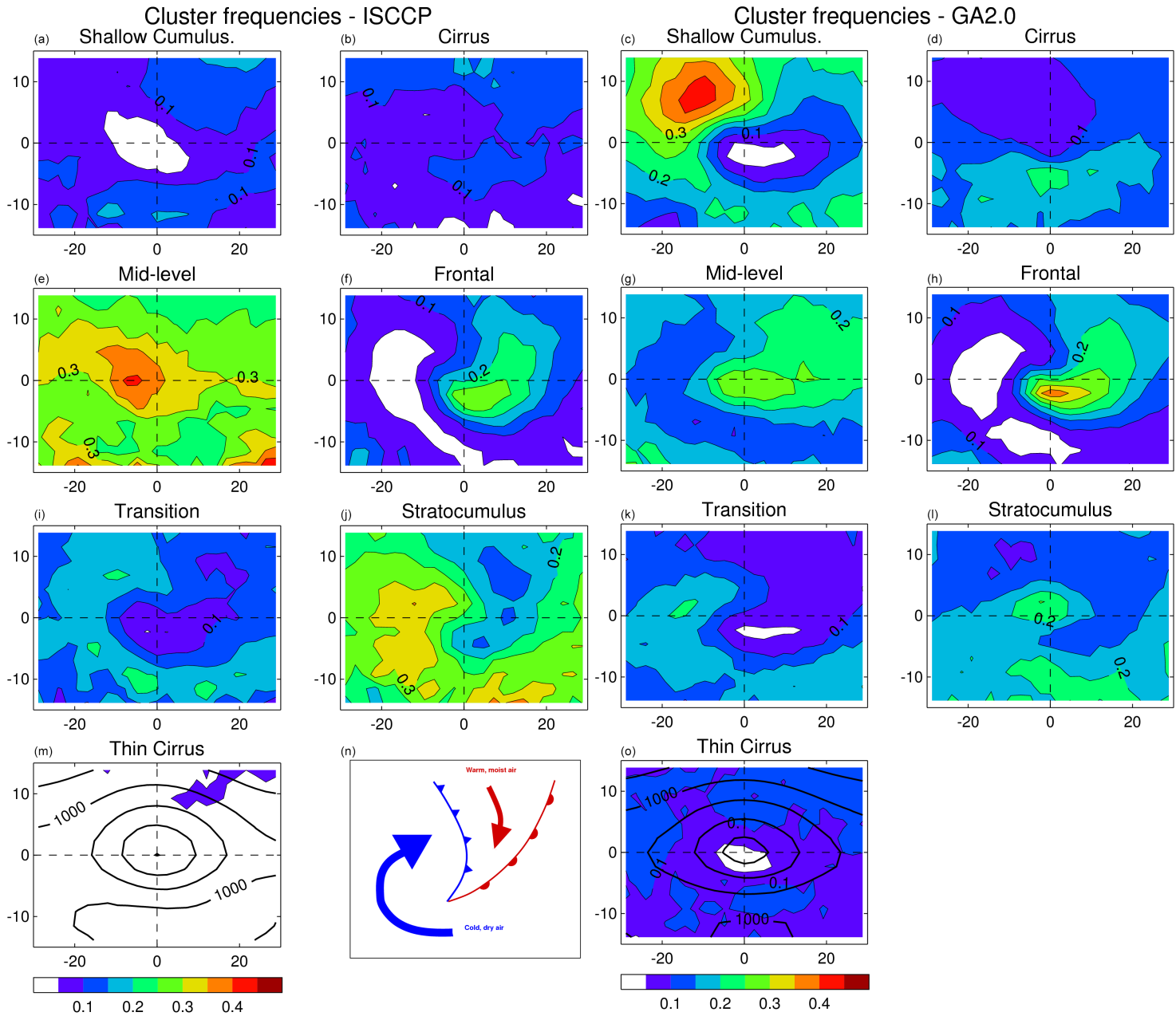

Figure 14. Relative frequency of occurrence of ISCCP-derived cloud regimes composited on a cyclone-centred reference framework (left) obtained from ERA-40 daily mean sea level pressure and (right) for a model (GA2.0's) cloud regimes and mean sea level pressure. In (m) and (o), the thick contours show the mean sea level pressure with $8 \mathrm{hPa}$ intervals. (n) in the left panel is a schematic with the typical position of the fronts in the cyclone composite. Reprinted from Bodas-Salcedo et al. (2012), ()American Meteorological Society. Used with permission.

well understood. Watanabe et al. (2012) found that MIROC5 underestimates middle-top clouds much less than MIROC3 and that the cloud feedback in MIROC5 is much less positive than in MIROC3. One of the main reasons for this is an increase in middle-top clouds in response to global warming in MIROC5. Greater understanding of middle-level clouds and their associated feedbacks will be useful.

For high clouds, the Fixed Anvil Temperature (FAT) mechanism (Hartmann and Larson, 2002) suggests that the temperature of the detrained tropical anvils associated with deep convection remains unchanged in a warming climate, implying that the cloud altitude feedback is positive. This mechanism, however, does not explain whether the cloud amount will increase or decrease. In addition, high thin cirrus which spreads into the tropical transition layer may be associated with different feedback mechanisms. High cloud amount tends to decrease in current conventional GCMs
(Zelinka et al., 2012), but a global cloud-resolving model shows an increase (Tsushima et al., 2014), suggesting that the response could be dependent on certain parameterization schemes, in particular convection and microphysics. Further evaluation of high clouds and examination of possible high cloud amount feedback mechanisms will clearly be necessary. Radar and lidar reflectivity-height histograms from CloudSat and CALIPSO were used to evaluate cloud amount and vertical profiles of high clouds (Kodama et al., 2012; Williams et al., 2015). Histograms such as these and other diagnostics using these data should be useful for this work.

With regard to physical processes, changes in the thermodynamic phase in some clouds are expected in a warming climate (Senior and Mitchell, 1993). Tsushima et al. (2006) highlighted the importance of evaluating the ratio of ice and liquid in mixed-phase clouds in simulations of the current climate because it determines how large the phase change might 

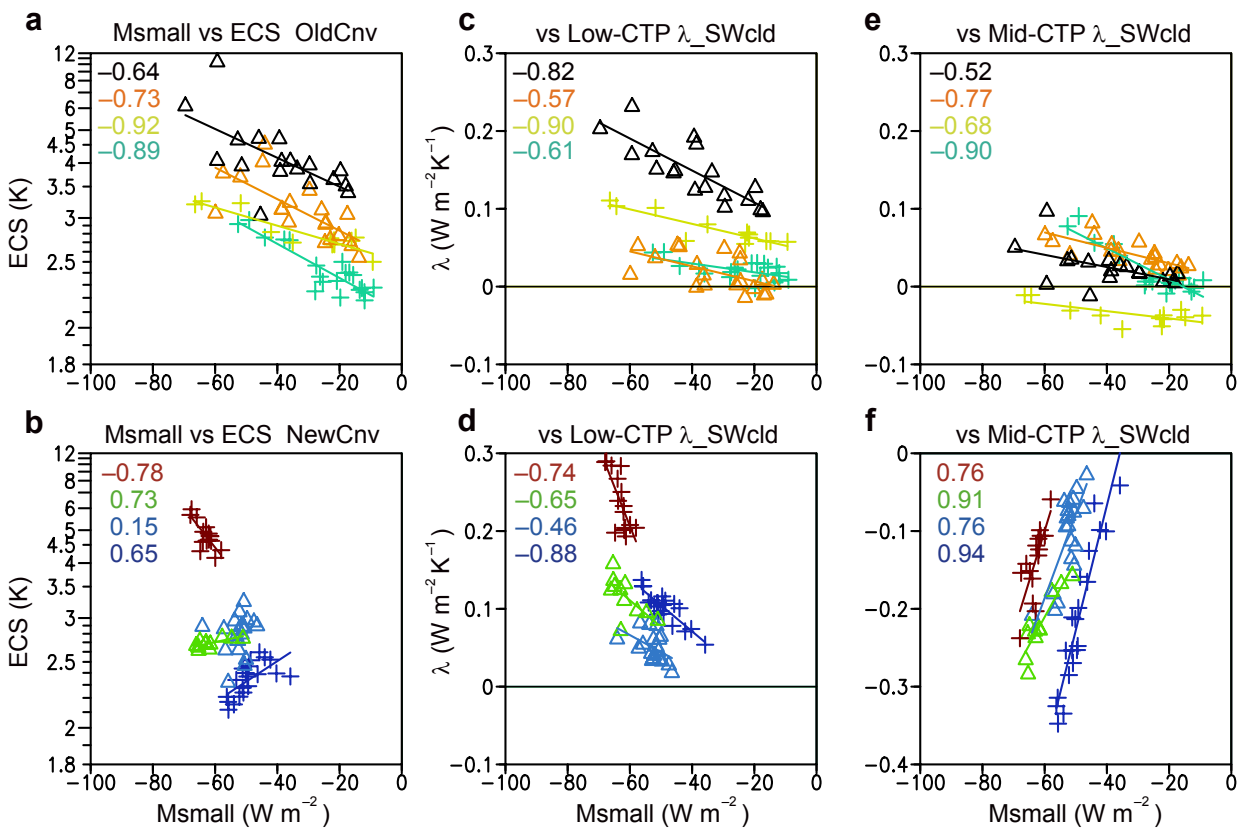

Figure 15. (a) Scatterplot of $M_{\text {small }}\left(\mathrm{W} \mathrm{m}^{-2}\right.$; small-scale mixing) and ECS (K) for ensembles with an old convective scheme (OldCnv) subset. Values at top left in the panels indicate correlation coefficients of the individual perturbed physics ensembles (PPEs); (c) $M_{\text {small }}$ and shortwave cloud feedback parameter $\lambda_{S \mathrm{Wcld}}\left(\mathrm{W} \mathrm{m}^{-2} \mathrm{~K}^{-1}\right)$ in bins of 1.3-23 for $\tau$ and 800-1000 hPa for cloud-top pressure (CTP); and (e) $M_{\text {small }}$ and $\lambda_{S W c l d}$ in bins of 23-60 for $\tau$ and 440-680 hPa for CTP. (b), (d), and (f): as in (a), (c), and (e) but for ensembles with a new convective scheme (NewCnv) subset. Reprinted from Kamae et al. (2016), (CAmerican Meteorological Society. Used with permission.

be under climate change. An underestimate of the relative amount of supercooled liquid water has been found in GCMs (Cesana et al., 2015; Tan et al., 2015). Tan et al. (2015) demonstrated that, as a consequence of the larger increase in liquid water from excessive ice water in the control climate, models could underestimate climate sensitivity. BodasSalcedo et al. (2016) used a cyclone-composite technique, and quantified the contribution of different regions around cyclone centres to the solar radiation budget and the feedback over the Southern Ocean. These methodologies and diagnostics could be useful for evaluating mixed-phase clouds in models.

Understanding clouds and cloud feedbacks as a part of dynamical systems and their response to climate change will also be important. Some dynamical responses are known to be robust among GCMs, such as the expansion of the Hadley cell (e.g. Seidel et al., 2008; Johanson and Fu, 2009) and the poleward shift of the mid-latitude jets (e.g. Yin, 2005; Wu et al., 2011; Barnes and Polvani, 2013). Grise and Polvani (2016) investigated the impact of these dynamical responses to climate sensitivity using CMIP5 models and found that in the Southern Hemisphere inter-model differences in the value of ECS explain $\sim 60 \%$ of the inter-model variance in the annual-mean Hadley cell expansion but just $\sim 20 \%$ of the variance in the annual-mean mid-latitude jet response. Tselioudis et al. (2016) investigated the relation- ship between interannual variations of the latitudinal position of clouds and their radiative effects and those in the Hadley cell and the mid-latitude jets. They found that the interannual variations of the locations of high clouds and the Hadley cell are correlated significantly, but did not find a robust correlation between clouds and the mid-latitude jets. Development of diagnostics which evaluate the representation of clouds within the major large-scale dynamical systems and their variations will therefore be useful. Metrics that explicitly include measures of circulation or water vapour and their relationships with clouds (e.g. the vapour-cloud relationships described by Bennhold and Sherwood, 2008) are likely to aid the understanding of cloud errors in models.

This paper describes only those emergent constraints which are currently included in the catalogue. Various emergent constraints for ECS have been proposed using both the CMIP3 and CMIP5 models (Klein and Hall, 2015), and more will undoubtedly be developed in the future. Development of emergent constraints for climate sensitivity or particular climate feedbacks which are underpinned by clear hypotheses and related to physical processes will be required.

We anticipate that the CFMIP diagnostic codes catalogue will continue to expand and invite additional contributions to further support the community to analyse CMIP6 outputs and to help develop and improve our understanding of cloud processes and cloud feedbacks. 
Code availability. Each repository is linked to the CFMIP webpage and can be found on the diagnostics code page there: https:// www.earthsystemcog.org/projects/cfmip/. The following page also has links to metrics that are included in the catalogue: https: //github.com/tsussi/cfmip-diagnostics-code-repository. CMIP data are available through the PCMDI CMIP page: http://www-pcmdi. 1lnl.gov/projects/cmip/. CFMIP1 and CFMIP2 data can be found under CMIP3 and CMIP5, respectively.

\section{The Supplement related to this article is available online at https://doi.org/10.5194/gmd-10-4285-2017- supplement.}

Competing interests. The authors declare that they have no conflict of interest.

Acknowledgements. We are grateful to Mark Ringer and Gill Martin for helpful comments on the manuscript. This work was supported by the Joint UK BEIS/Defra Met Office Hadley Centre Climate Programme (GA01101). This work was originally funded by the European Union Seventh Framework Programme (FP7/2007-2013) under grant agreement no. 244067 via the EU Cloud Intercomparison and Process Study Evaluation Project (EUCLIPSE). Xin Qu, Mark D. Zelinka and Stephen A. Klein are supported by the United States Department of Energy's Regional and Global Climate Modelling Program under the project "Identifying Robust Cloud Feedbacks in Observations and Models". The work of Mark D. Zelinka and Stephen A. Klein was performed under the auspices of the United States Department of Energy by Lawrence Livermore National Laboratory under contract DEAC52-07NA27344. Kentaroh Suzuki is supported by the NOAA's Climate Program Office's Modeling, Analysis, Predictions and Projections programme with grant no. NA15OAR4310153 and by the Integrated Research Program for Advancing Climate Models (TOUGOU programme) from the Ministry of Education, Culture, Sports, Science and Technology (MEXT), Japan.

Edited by: Simon Unterstrasser

Reviewed by: two anonymous referees

\section{References}

Anderberg, M.: Cluster analysis for applications, Academic Press, New York, 359 pp., 1973.

Barnes, E. and Polvani, L.: Response of the Midlatitude Jets, and of Their Variability, to Increased Greenhouse Gases in the CMIP5 Models, J. Climate, 26, 7117-7135, https://doi.org/10.1175/JCLI-D-12-00536.1, 2013.

Bennhold, F. and Sherwood, S.: Erroneous relationships among humidity and cloud forcing variables in three global climate models, J. Climate, 21, 4190-4206, https://doi.org/10.1175/2008JCLI1969.1, 2008.

Bodas-Salcedo, A., Webb, M., Bony, S., Chepfer, H., Dufresne, J., Klein, S., Zhang, Y., Marchand, R., Haynes, J., Pincus,
R., and John, V.: COSP Satellite simulation software for model assessment, B. Am. Meteorol. Soc., 92, 1023-1043, https://doi.org/10.1175/2011BAMS2856.1, 2011.

Bodas-Salcedo, A., Williams, K., Field, P., and Lock, A.: The Surface Downwelling Solar Radiation Surplus over the Southern Ocean in the Met Office Model: The Role of Midlatitude Cyclone Clouds, J. Climate, 25, 7467-7486, https://doi.org/10.1175/JCLI-D-11-00702.1, 2012.

Bodas-Salcedo, A., Andrews, T., Karmalkar, A., and Ringer, M.: Cloud liquid water path and radiative feedbacks over the Southern Ocean, Geophys. Res. Lett., 43, 10938-10946, https://doi.org/10.1002/2016GL070770, 2016

Bony, S., Stevens, B., Frierson, D., Jakob, C., Kageyama, M., Pincus, R., Shepherd, T., Sherwood, S., Siebesma, A., Sobel, A., Watanabe, M., and Webb, M.: Clouds, circulation and climate sensitivity, Nat. Geosci., 8, 261-268, https://doi.org/10.1038/NGEO2398, 2015.

Boucher, O., Randall, D., Artaxo, P., Bretherton, C., Feingold, G., Forster, P., Kerminen, V.-M., Kondo, Y., Liao, H., Lohmann, U., Rasch, P., Satheesh, S. K., Sherwood, S., Stevens, B., and Zhang, X. Y.: Clouds and Aerosols, Cambridge, United Kingdom and New York, NY, USA, 2013.

Bretherton, C., Blossey, P., and Jones, C.: Mechanisms of marine low cloud sensitivity to idealized climate perturbations: A single-LES exploration extending the CGILS cases, Journal of Advances in Modeling Earth Systems, 5, 316-337, https://doi.org/10.1002/jame.20019, 2013.

Brient, F. and Schneider, T.: Constraints on Climate Sensitivity from Space-Based Measurements of Low-Cloud Reflection, J. Climate, 29, 5821-5835, https://doi.org/10.1175/JCLI-D-150897.1, 2016.

Brient, F., Schneider, T., Tan, Z., Bony, S., Qu, X., and Hall, A.: Shallowness of tropical low clouds as a predictor of climate models' response to warming, Clim. Dynam., 47, 433-449, https://doi.org/10.1007/s00382-015-2846-0, 2016.

Cesana, G., Waliser, D., Jiang, X., and Li, J.: Multimodel evaluation of cloud phase transition using satellite and reanalysis data, J. Geophys. Res.-Atmos., 120, 7871-7892, https://doi.org/10.1002/2014JD022932, 2015.

Chepfer, H., Bony, S., Winker, D., Cesana, G., Dufresne, J., Minnis, P., Stubenrauch, C., and Zeng, S.: The GCM-Oriented CALIPSO Cloud Product (CALIPSO-GOCCP), J. Geophys. Res.-Atmos., 115, D00H16, https://doi.org/10.1029/2009JD012251, 2010.

Dee, D., Uppala, S., Simmons, A., Berrisford, P., Poli, P., Kobayashi, S., Andrae, U., Balmaseda, M., Balsamo, G., Bauer, P., Bechtold, P., Beljaars, A., van de Berg, L., Bidlot, J., Bormann, N., Delsol, C., Dragani, R., Fuentes, M., Geer, A., Haimberger, L., Healy, S., Hersbach, H., Holm, E., Isaksen, L., Kallberg, P., Kohler, M., Matricardi, M., McNally, A., Monge-Sanz, B., Morcrette, J., Park, B., Peubey, C., de Rosnay, P., Tavolato, C., Thepaut, J., and Vitart, F.: The ERA-Interim reanalysis: configuration and performance of the data assimilation system, Q. J. Roy. Meteor. Soc., 137, 553-597, https://doi.org/10.1002/qj.828, 2011.

Dufresne, J., Foujols, M., Denvil, S., Caubel, A., Marti, O., Aumont, O., Balkanski, Y., Bekki, S., Bellenger, H., Benshila, R., Bony, S., Bopp, L., Braconnot, P., Brockmann, P., Cadule, P., Cheruy, F., Codron, F., Cozic, A., Cugnet, D., de Noblet, N., Duvel, J., Ethe, C., Fairhead, L., Fichefet, T., Flavoni, S., Friedlingstein, P., 
Grandpeix, J., Guez, L., Guilyardi, E., Hauglustaine, D., Hourdin, F., Idelkadi, A., Ghattas, J., Joussaume, S., Kageyama, M., Krinner, G., Labetoulle, S., Lahellec, A., Lefebvre, M., Lefevre, F., Levy, C., Li, Z., Lloyd, J., Lott, F., Madec, G., Mancip, M., Marchand, M., Masson, S., Meurdesoif, Y., Mignot, J., Musat, I., Parouty, S., Polcher, J., Rio, C., Schulz, M., Swingedouw, D., Szopa, S., Talandier, C., Terray, P., Viovy, N., and Vuichard, N.: Climate change projections using the IPSL-CM5 Earth System Model: from CMIP3 to CMIP5, Clim. Dynam., 40, 2123-2165, https://doi.org/10.1007/s00382-012-1636-1, 2013.

Eyring, V., Righi, M., Lauer, A., Evaldsson, M., Wenzel, S., Jones, C., Anav, A., Andrews, O., Cionni, I., Davin, E. L., Deser, C., Ehbrecht, C., Friedlingstein, P., Gleckler, P., Gottschaldt, K.D., Hagemann, S., Juckes, M., Kindermann, S., Krasting, J., Kunert, D., Levine, R., Loew, A., Mäkelä, J., Martin, G., Mason, E., Phillips, A. S., Read, S., Rio, C., Roehrig, R., Senftleben, D., Sterl, A., van Ulft, L. H., Walton, J., Wang, S., and Williams, K. D.: ESMValTool (v1.0) - a community diagnostic and performance metrics tool for routine evaluation of Earth system models in CMIP, Geosci. Model Dev., 9, 1747-1802, https://doi.org/10.5194/gmd-9-1747-2016, 2016.

$\mathrm{Fu}$, Q. and Liou, K.: On the correlated k-distribution method for radiative-transfer in nonhomogeneous atmospheres, J. Atmos. Sci., 49, 2139-2156, https://doi.org/10.1175/15200469(1992)049<2139:OTCDMF>2.0.CO;2, 1992.

Gettleman, A. and Sherwood, S. C.: Process Responsible for Cloud Feedback, Curr. Clim. Change Rep., 2, 179-189, https://doi.org/10.1007/s40641-016-0052-8, 2016.

Gleckler, P., Taylor, K., and Doutriaux, C.: Performance metrics for climate models, J. Geophys. Res.-Atmos., 113, D06104, https://doi.org/10.1029/2007JD008972, 2008.

Gleckler, P. J., Doutriaux, C., Durack, P. J., Taylor, K. E., Zhang, Y., Williams, D. N., Mason, E., and Servonnat, J.: A more powerful reality test for climate models, in: Eos, American Geophysical Union, 2016.

Grise, K. and Polvani, L.: Is climate sensitivity related to dynamical sensitivity?, J. Geophys. Res.-Atmos., 121, 5159-5176, https://doi.org/10.1002/2015JD024687, 2016.

Hartmann, D. and Larson, K.: An important constraint on tropical cloud - climate feedback, Geophys. Res. Lett., 29, 12-1-12-4, https://doi.org/10.1029/2002GL015835, 2002.

Hogan, R., Schafer, S., Klinger, C., Chiu, J., and Mayer, B.: Representing 3-D cloud radiation effects in twostream schemes: 2. Matrix formulation and broadband evaluation, J. Geophys. Res.-Atmos., 121, 8583-8599, https://doi.org/10.1002/2016JD024875, 2016.

Hourdin, F., Foujols, M., Codron, F., Guemas, V., Dufresne, J., Bony, S., Denvil, S., Guez, L., Lott, F., Ghattas, J., Braconnot, P., Marti, O., Meurdesoif, Y., and Bopp, L.: Impact of the LMDZ atmospheric grid configuration on the climate and sensitivity of the IPSL-CM5A coupled model, Clim. Dynam., 40, 2167-2192, https://doi.org/10.1007/s00382-012-1411-3, 2013a.

Hourdin, F., Grandpeix, J., Rio, C., Bony, S., Jam, A., Cheruy, F., Rochetin, N., Fairhead, L., Idelkadi, A., Musat, I., Dufresne, J., Lahellec, A., Lefebvre, M., and Roehrig, R.: LMDZ5B: the atmospheric component of the IPSL climate model with revisited parameterizations for clouds and convection, Clim. Dynam., 40, 2193-2222, https://doi.org/10.1007/s00382-012-1343-y, 2013b.
Johanson, C. and Fu, Q.: Hadley Cell Widening: Model Simulations versus Observations, J. Climate, 22, 2713-2725, https://doi.org/10.1175/2008JCLI2620.1, 2009.

Kamae, Y., Shiogama, H., Watanabe, M., Ogura, T., Yokohata, T., and Kimoto, M.: Lower-Tropospheric Mixing as a Constraint on Cloud Feedback in a Multiparameter Multiphysics Ensemble, J. Climate, 29, 6259-6275, https://doi.org/10.1175/JCLI-D-160042.1, 2016.

Kim, D., Sperber, K., Stern, W., Waliser, D., Kang, I., Maloney, E., Wang, W., Weickmann, K., Benedict, J., Khairoutdinov, M., Lee, M., Neale, R., Suarez, M., Thayer-Calder, K., and Zhang, G.: Application of MJO Simulation Diagnostics to Climate Models, J. Climate, 22, 6413-6436, https://doi.org/10.1175/2009JCLI3063.1, 2009.

Kim, D., Xavier, P., Maloney, E., Wheeler, M., Waliser, D., Sperber, K., Hendon, H., Zhang, C., Neale, R., Hwang, Y., and Liu, H.: Process-Oriented MJO Simulation Diagnostic: Moisture Sensitivity of Simulated Convection, J. Climate, 27, 5379-5395, https://doi.org/10.1175/JCLI-D-13-00497.1, 2014.

Klein, S., Zhang, Y., Zelinka, M., Pincus, R., Boyle, J., and Gleckler, P.: Are climate model simulations of clouds improving? An evaluation using the ISCCP simulator, J. Geophys. Res.-Atmos., 118, 1329-1342, https://doi.org/10.1002/jgrd.50141, 2013.

Klein, S. A. and Hall, A.: Emergent constraints for cloud feedbacks, Current Climate Change Report, 1, 276-287, https://doi.org/10.1007/s40641-015-0027-1, 2015.

Kodama, C., Noda, A., and Satoh, M.: An assessment of the cloud signals simulated by NICAM using ISCCP, CALIPSO, and CloudSat satellite simulators, J. Geophys. Res.-Atmos., 117, D12210, https://doi.org/10.1029/2011JD017317, 2012.

Konsta, D., Chepfer, H., and Dufresne, J.: A process oriented characterization of tropical oceanic clouds for climate model evaluation, based on a statistical analysis of daytime A-train observations, Clim. Dynam., 39, 2091-2108, https://doi.org/10.1007/s00382-012-1533-7, 2012.

Konsta, D., Dufresne, J. L., Chepfer, H., Idelkali, A., and Cesana, G.: Use of A-train satellite observations (CALIPSO-PARASOL) to evaluate tropical cloud properties in the LMDZ5 GCM, Clim. Dynam., 47, 1263-1284, https://doi.org/10.1007/s00382015-2900-y, 2015.

Marchand, R., Mace, G., Ackerman, T., and Stephens, G.: Hydrometeor detection using Cloudsat - An earth-orbiting 94$\mathrm{GHz}$ cloud radar, J. Atmos. Ocean. Tech., 25, 519-533, https://doi.org/10.1175/2007JTECHA1006.1, 2008.

Marchand, R., Haynes, J., Mace, G., Ackerman, T., and Stephens, G.: A comparison of simulated cloud radar output from the multiscale modeling framework global climate model with CloudSat cloud radar observations, J. Geophys. Res.-Atmos., 114, D00A20, https://doi.org/10.1029/2008JD009790, 2009.

Masunaga, H., Matsui, T., Tao, W., Hou, A., Kummerow, C., Nakajima, T., Bauer, P., Olson, W., Sekiguchi, M., and Nakajima, T.: Satellite Data Simulator Unit A Multisensor, Multispectral Satellite Simulator Package, B. Am. Meteorol. Soc., 91, 1625-1632, https://doi.org/10.1175/2010BAMS2809.1, 2010.

Medeiros, B. and Stevens, B.: Revealing differences in GCM representations of low clouds, Clim. Dynam., 36, 385-399, https://doi.org/10.1007/s00382-009-0694-5, 2011.

Nakajima, T., Suzuki, K., and Stephens, G.: Droplet Growth in Warm Water Clouds Observed by the A-Train. Part 
II: A Multisensor View, J. Atmos. Sci., 67, 1897-1907, https://doi.org/10.1175/2010JAS3276.1, 2010.

Nam, C., Bony, S., Dufresne, J., and Chepfer, H.: The "too few, too bright" tropical low-cloud problem in CMIP5 models, Geophys. Res. Lett., 39, L21801, https://doi.org/10.1029/2012GL053421, 2012.

Nam, C. and Quaas, J.: Evaluation of Clouds and Precipitation in the ECHAM5 General Circulation Model Using CALIPSO and CloudSat Satellite Data, J. Climate, 25, 49754992, https://doi.org/10.1175/JCLI-D-11-00347.1, 2012.

Parol, F., Buriez, J., Vanbauce, C., Riedi, J., Labonnote, L., Doutriaux-Boucher, M., Vesperini, M., Seze, G., Couvert, P., Viollier, M., Breon, F., Schlussel, P., Stuhlmann, R., Campbell, J., and Erickson, C.: Review of capabilities of multi-angle and polarization cloud measurements from POLDER, Climate Change Processes in the Stratosphere, Earth-Atmosphere-Ocean Systems, and Oceanographic Processes From Satellite Data, 33, 1080-1088, https://doi.org/10.1016/S0273-1177(03)007348, 2004.

Pincus, R., Batstone, C., Hofmann, R., Taylor, K., and Glecker, P.: Evaluating the present-day simulation of clouds, precipitation, and radiation in climate models, J. Geophys. Res.-Atmos., 113, D14209, https://doi.org/10.1029/2007JD009334, 2008.

Pincus, R., Platnick, S., Ackerman, S., Hemler, R., and Hofmann, R.: Reconciling Simulated and Observed Views of Clouds: MODIS, ISCCP, and the Limits of Instrument Simulators, J. Climate, 25, 4699-4720, https://doi.org/10.1175/JCLI-D-1100267.1, 2012.

Platnick, S., King, M., Ackerman, S., Menzel, W., Baum, B., Riedi, J., and Frey, R.: The MODIS cloud products: Algorithms and examples from Terra, IEEE T. Geosci. Remote, 41, 459-473, https://doi.org/10.1109/TGRS.2002.808301, 2003.

Qu, X., Hall, A., Klein, S., and Caldwell, P.: On the spread of changes in marine low cloud cover in climate model simulations of the 21st century, Clim. Dynam., 42, 2603-2626, https://doi.org/10.1007/s00382-013-1945-z, 2014.

Randall, D., Wood, R., Bony, S., Colman, R., Fichefet, T., Fyfe, J., Kattsov, V., Pitman, A., Shukla, J., Srinivasan, J., Stouffer, R., Sumi, A., and Taylor, K.: Climate models and their evaluation, in: Climate Change 2007: The physical science basis, Contribution of Working Group I to the Fourth Assessment Report of the IPCC (FAR), Cambridge University Press, 589-662, 2007.

Reichler, T. and Kim, J.: How well do coupled models simulate today's climate?, B. Am. Meteorol. Soc., 89, 303-311, https://doi.org/10.1175/BAMS-89-3-303, 2008.

Reynolds, R., Rayner, N., Smith, T., Stokes, D., and Wang, W.: An improved in situ and satellite SST analysis for climate, J. Climate, 15, 1609-1625, https://doi.org/10.1175/15200442(2002)015<1609:AIISAS>2.0.CO;2, 2002.

Rossow, W. and Schiffer, R.: Advances in understanding clouds from ISCCP, B. Am. Meteorol. Soc., $\quad 80, \quad 2261-2287$, https://doi.org/10.1175/15200477(1999)080<2261:AIUCFI>2.0.CO;2, 1999.

Rossow, W., Tselioudis, G., Polak, A., and Jakob, C.: Tropical climate described as a distribution of weather states indicated by distinct mesoscale cloud property mixtures, Geophys. Res. Lett., 32, L21812, https://doi.org/10.1029/2005GL024584, 2005.
Seidel, D., Fu, Q., Randel, W., and Reichler, T.: Widening of the tropical belt in a changing climate, Nat. Geosci., 1, 21-24, https://doi.org/10.1038/ngeo.2007.38, 2008.

Senior, C. and Mitchell, J.: Carbon-dioxide and climate - the impact of cloud parameterization, J. Climate, 6, 393-418, https://doi.org/10.1175/15200442(1993)006<0393:CDACTI>2.0.CO;2, 1993.

Sherwood, S., Bony, S., and Dufresne, J.: Spread in model climate sensitivity traced to atmospheric convective mixing, Nature, 505, 37-42, https://doi.org/10.1038/nature12829, 2014.

Suzuki, K., Nakajima, T., and Stephens, G.: Particle Growth and Drop Collection Efficiency of Warm Clouds as Inferred from Joint CloudSat and MODIS Observations, J. Atmos. Sci., 67, 3019-3032, https://doi.org/10.1175/2010JAS3463.1, 2010.

Suzuki, K., Stephens, G., Bodas-Salcedo, A., Wang, M., Golaz, J., Yokohata, T., and Koshiro, T.: Evaluation of the Warm Rain Formation Process in Global Models with Satellite Observations, J. Atmos. Sci., 72, 3996-4014, https://doi.org/10.1175/JAS-D-140265.1, 2015.

Tan, I., Storelvmo, T., and Zelinka, M. D.: Observational constraints on mixed-phase clouds imply higher climate sensitivity, Science, 352, 224-227, https://doi.org/10.1126/science.aad5300, 2015.

Tselioudis, G., Lipat, B., Konsta, D., Grise, K., and Polvani, L.: Midlatitude cloud shifts, their primary link to the Hadley cell, and their diverse radiative effects, Geophys. Res. Lett., 43, 45944601, https://doi.org/10.1002/2016GL068242, 2016.

Tsushima, Y., Emori, S., Ogura, T., Kimoto, M., Webb, M., Williams, K., Ringer, M., Soden, B., Li, B., and Andronova, N.: Importance of the mixed-phase cloud distribution in the control climate for assessing the response of clouds to carbon dioxide increase: a multi-model study, Clim. Dynam., 27, 113-126, https://doi.org/10.1007/s00382-006-0127-7, 2006.

Tsushima, Y., Ringer, M., Webb, M., and Williams, K.: Quantitative evaluation of the seasonal variations in climate model cloud regimes, Clim. Dynam., 41, 2679-2696, https://doi.org/10.1007/s00382-012-1609-4, 2013.

Tsushima, Y., Iga, S., Tomita, H., Satoh, M., Noda, A., and Webb, M.: High cloud increase in a perturbed SST experiment with a global nonhydrostatic model including explicit convective processes, Journal of Advances in Modeling Earth Systems, 6, 571585, https://doi.org/10.1002/2013MS000301, 2014.

Tsushima, Y., Ringer, M. A., Koshiro, T., Kawai, H., Roehrig, R., Cole, J., Watanabe, M., Yokohata, T., Bodas-Salcedo, A., Williams, K. D., and Webb, M. J.: Robustness, uncertainties, and emergent constraints in the radiative responses of stratocumulus regimes to future warming, Clim. Dynam., 46, 3025-3039, https://doi.org/10.1007/s00382-015-2750-7, 2015.

Waliser, D., Sperber, K., Hendon, H., Kim, D., Wheeler, M., Weickmann, K., Zhang, C., Donner, L., Gottschalck, J., Higgins, W., Kang, I., Legler, D., Moncrieff, M., Vitart, F., Wang, B., Wang, W., Woolnough, S., Maloney, E., Schubert, S., Stern, W., Oscillation, C. M.-J., and Oscillation, C. M.J.: MJO Simulation Diagnostics, J. Climate, 22, 3006-3030, https://doi.org/10.1175/2008JCLI2731.1, 2009.

Watanabe, M., Shiogama, H., Yokohata, T., Kamae, Y., Yoshimori, M., Ogura, T., Annan, J., Hargreaves, J., Emori, S., and Kimoto, M.: Using a Multiphysics Ensemble for Exploring Diversity in Cloud-Shortwave Feedback in GCMs, J. Climate, 25, 5416-5431, https://doi.org/10.1175/JCLI-D-11-00564.1, 2012. 
Webb, M. and Lock, A.: Coupling between subtropical cloud feedback and the local hydrological cycle in a climate model, Clim. Dynam., 41, 1923-1939, https://doi.org/10.1007/s00382012-1608-5, 2013.

Webb, M. J., Andrews, T., Bodas-Salcedo, A., Bony, S., Bretherton, C. S., Chadwick, R., Chepfer, H., Douville, H., Good, P., Kay, J. E., Klein, S. A., Marchand, R., Medeiros, B., Siebesma, A. P., Skinner, C. B., Stevens, B., Tselioudis, G., Tsushima, Y., and Watanabe, M.: The Cloud Feedback Model Intercomparison Project (CFMIP) contribution to CMIP6, Geosci. Model Dev., 10, 359-384, https://doi.org/10.5194/gmd-10-359-2017, 2017.

Williams, K. and Tselioudis, G.: GCM intercomparison of global cloud regimes: present-day evaluation and climate change response, Clim. Dynam., 29, 231-250, https://doi.org/10.1007/s00382-007-0232-2, 2007.

Williams, K. and Webb, M.: A quantitative performance assessment of cloud regimes in climate models, Clim. Dynam., 33, 141-157, https://doi.org/10.1007/s00382-008-0443-1, 2009.

Williams, K. D., Harris, C. M., Bodas-Salcedo, A., Camp, J., Comer, R. E., Copsey, D., Fereday, D., Graham, T., Hill, R., Hinton, T., Hyder, P., Ineson, S., Masato, G., Milton, S. F., Roberts, M. J., Rowell, D. P., Sanchez, C., Shelly, A., Sinha, B., Walters, D. N., West, A., Woollings, T., and Xavier, P. K.: The Met Office Global Coupled model 2.0 (GC2) configuration, Geosci. Model Dev., 8, 1509-1524, https://doi.org/10.5194/gmd-8-15092015, 2015.

Winker, D., Hunt, W., and McGill, M.: Initial performance assessment of CALIOP, Geophys. Res. Lett., 34, L19803, https://doi.org/10.1029/2007GL030135, 2007.
Wu, Y., Ting, M., Seager, R., Huang, H. P., and Cane, M. A.: Changes in storm tracks and energy transports in a warmer climate simulated by the GFDL CM2.1 model, Clim. Dynam., 37, 53-72, https://doi.org/10.1007/s00382-010-0776-4, 2011.

Yin, J.: A consistent poleward shift of the storm tracks in simulations of the 21st century climate, Geophys. Res. Lett., 32, L18701, https://doi.org/10.1029/2005GL023684, 2005.

Zelinka, M., Klein, S., and Hartmann, D.: Computing and Partitioning Cloud Feedbacks Using Cloud Property Histograms. Part I: Cloud Radiative Kernels, J. Climate, 25, 3715-3735, https://doi.org/10.1175/JCLI-D-11-00248.1, 2012.

Zhang, M., Lin, W., Klein, S., Bacmeister, J., Bony, S., Cederwall, R., Del Genio, A., Hack, J., Loeb, N., Lohmann, U., Minnis, P., Musat, I., Pincus, R., Stier, P., Suarez, M., Webb, M., Wu, J., Xie, S., Yao, M., and Zhang, J.: Comparing clouds and their seasonal variations in 10 atmospheric general circulation models with satellite measurements, J. Geophys. Res.-Atmos., 110, D15S02, https://doi.org/10.1029/2004JD005021, 2005.

Zhao, M., Golaz, J., Held, I., Ramaswamy, V., Lin, S., Ming, Y., Ginoux, P., Wyman, B., Donner, L., Paynter, D., and Guo, H.: Uncertainty in Model Climate Sensitivity Traced to Representations of Cumulus Precipitation Microphysics, J. Climate, 29, 543-560, https://doi.org/10.1175/JCLI-D-15-0191.1, 2016. 